\title{
A Portrait of a Place: A New Frame to View Artwork in the Academic Library
}

by

\section{Celia Andrea Mallory Austin}

Submitted to the School of Information Management,

Victoria University of Wellington

in partial fulfilment of the requirements for the degree of

Master of Information Studies 


\section{Contents}

Acknowledgements 3

List of Illustrations 4

$\begin{array}{lr}\text { Introduction } & 6\end{array}$

$\begin{array}{ll}\text { Background } & 6\end{array}$

$\begin{array}{ll}\text { Project Structure } & 7\end{array}$

$\begin{array}{lr}\text { Literature Review } & 8\end{array}$

Methodology 18

$\begin{array}{lr}\text { Selection and description of the research site } & 18\end{array}$

$\begin{array}{lr}\text { Theoretical framework } & 19\end{array}$

$\begin{array}{ll}\text { Data analysis } & 22\end{array}$

Role of the researcher 23

Possible research delimitations 24

Results $\quad 26$

Analyses of observational data $\quad 26$

Physical distribution and location of artwork 31

Analyses of interview data 34

I. Valuing artwork in the academic library setting 35

II. Seeing artwork as information 40

III. Motivations for displaying artwork in the academic library setting 45

IV. Challenges of hosting artwork in the academic library 51

V. Considering the academic library as a public art space 55

VI. Looking through the Window 59

$\begin{array}{ll}\text { Discussion } & 64\end{array}$

Recommendations for future research $\quad 67$

$\begin{array}{lr}\text { Conclusion } & 69\end{array}$

$\begin{array}{ll}\text { Bibliography } & 70\end{array}$

$\begin{array}{ll}\text { Appendix I } & 74\end{array}$

$\begin{array}{ll}\text { Appendix II } & 75\end{array}$

$\begin{array}{ll}\text { Appendix III } & 76\end{array}$

$\begin{array}{ll}\text { Appendix IV } & 77\end{array}$ 


\section{Acknowledgements}

First and foremost, I would like to thank my supervisor Shannon Wellington for her guidance and encouragement in all aspects of this project.

I would like to thank the University of Auckland for graciously allowing me to use their General Library as the case for this project, and for permission to include photographs of the artwork.

I would like to express my gratitude to all the participants who willingly gave their time, effort and thoughts during the process of interviewing.

I would also like to thank Linda Tyler for her invaluable assistance to ensure the foundations of this project were steady.

In addition, I would like to thank the librarians of Victoria University, for their exceptional assistance.

Thanks must also go to my friends for their continual encouragement.

Finally, thanks are to my family (and Bertie) for their support, diligent proof-reading, and love.

Celia Austin

June 2013 


\section{List of Illustrations}

1. Placement of Window (showing Radio Strainer by Alys Longley and Jeffrey Holdaway, May 2013), General Library entranceway

2. Close-up of Window (showing Radio Strainer by Alys Longley and Jeffrey Holdaway, May 2013), General Library entranceway

3. Red Insects, Blue Triangles by Richard Killeen (1980), General Library entranceway (seen from library doors)

4. Sonic Panorama by Elizabeth Thomson (2002), Ground Floor,

General Library

5. Carved Maori panel (left) and Niho by Jody Walters (n.d.), Ground Floor, General Library

6. 35/35 by Phillip Trusttum (1976), Ground Floor, General Library

7. Artwork in the Special Collections Room, Ground Floor, General Library

8. Bust of Dante (artist unknown, n.d.), Special Collections Room, Ground Floor, General Library

9. Sam Hunt, Bottle Creek by Robin White (1970), First Floor, General Library

10. Blade Healers by Rohan Wealleans (2008), First Floor, General Library

11. How Maui Made the Sun Go Down by Pauline and James Yearbury (n.d.), First Floor (seen from Mezzanine Floor), General Library

12. He mihi ki nga Wairua Kaitiaki o te Whenua by Selwyn Muru (1997), First Floor (seen from Mezzanine Floor), General Library

13. Socket by Sarah Munro (2003), First Floor (seen from Mezzanine Floor), General Library

14. Kawaupaku Te Henga by Don Binney (1967, left) and He mihi ki nga Wairua Kaitiaki o te Whenua by Selwyn Muru (1997), seen from Mezzanine Floor), General Library

15. Untitled by Tom Kreisler (2008), stairwell between the Second and Third Floors, General Library

16. Artwork in the stairwell between the Third and Fourth Floors, General Library

17. Photograph showing the distribution of sunlight into the stairwells (pictured: the stairwell between the Second and Third Floors), General Library

18. Untitled by Daniel Malone (left, 2008) and Untitled by Ronnie van Hout (right, 2008), stairwell between the Fifth and Sixth Floors, General Library 
19. Enlargement from the Book of Hours by Helen Sandall (1969), Fifth Floor, General Library

20. Sirens by Liz Maw (2009), Sixth Floor, General Library 


\section{A Portrait of a Place: A New Frame to View Artwork in the Academic Library}

\section{Introduction}

The act of displaying artwork and art objects in academic libraries has been called both a "natural idea and common practice" (Cirasella and Deutsch, 2012, p. 2), but this position lacks a considered and critical analysis. The motivation for displaying artwork in academic libraries and an evaluation of its impact on the library environment, as perceived by librarians, similarly lacks meaningful examination. This absence of previous inquiry provides a major stimulus for this research project, which uses a case study approach to examine and explore the 'natural' preoccupation for displaying artwork in academic libraries, and additionally considers such environments as public art spaces.

\section{Background}

Academic libraries have long exhibited collections of artwork, as their goal to educate finds commonality with the cultural enrichment and stimulation provided by art. This duality has special relevance in light of recent research which suggests that academic libraries are undergoing significant changes to their traditional model of operation, becoming multidisciplinary and inclusive physical spaces (Gayton, 2008, p. 60). Artwork can be an impressive force in enhancing the cultural and intellectual life of libraries in academic institutions, which has repercussions for its staff, students and the greater public community.

This project addresses the following research problems:

- Is it relevant for an academic library to display artwork?

- Is there a purpose for artwork in the academic library?

- What benefits, and pitfalls, are seen as a result of an academic library hosting artwork?

- Can academic libraries be public art spaces? 
These questions will be explored and analysed in detail in a case study of a library in a tertiary institution noted for its diverse art collection, namely the General Library of the University of Auckland. The project will provide a novel research base, a combination of the disciplines of Art History and Information Studies, from which the views of academic librarians and other related parties are analysed. It will also extend the concept of a public art space to include the academic library setting, and evaluate the effect this has for an institution, its community of users, and the key stakeholders. The project will offer an overall contemporary portrait of an academic library's involvement with artwork and its role as a host for art. It will also explore broader themes relevant to the disciplines of Art History and Information Studies, and set the scene for future research using this blend of interests.

\section{Project Structure}

The presentation of this project has the following order. Firstly, the historic and current literature that associates art and libraries, and more specifically artwork in academic libraries will be explored, to provide the base for the methodology of the project and a description of the case and interview participants. The subsequent section will set out the theoretical framework for the observation and interview portions of the project, including the interview questions. The following section will analyse the observation and interview data, the role of the researcher, and the possible delimitations of the project, and the next section will deal with the data: firstly a report on the physical observations, and secondly with six reflections on the interviews with participants. The following section will discuss the data collected as a whole, with the last section illustrating recommended areas for future research. The project will end with final conclusions. 


\section{Literature Review}

\section{Historic rationale linking art and libraries}

The existing literature on the display of artwork in academic libraries is primarily North American based and is largely confined to providing recommendations for librarians faced with caring for artwork in their workplace. There is little research exploring why the academic library is an apparent natural home for an institution's art collection, nor is there an analysis of librarian perspectives on these issues.

Despite the limited investigations exploring why artwork is associated with academic libraries, the longstanding tradition that combines the two, both in images of libraries and in the rooms themselves, can be traced back to the Renaissance (Thornton, 1997, p. 1). The earliest form of private study favoured by scholars in this period was the studiolo, a small room in which its owner could retreat from the demands of the outside world to contemplate, read, and admire prized and beautiful possessions. These private study rooms were almost exclusively for the princely and landed elite, highlighting the lauded relationship between the prestige of education and artistic appreciation. In the images and detailed inventories that remain of studioli, it is evident that objects of aesthetic rarity were aligned with refined edification and the pursuit of intellectual stimulation.

Dora Thornton, a specialist in the Renaissance interior, asserts that the decorations, fittings and furnishings of a studiolo were carefully cultivated to exemplify the social virtues and education of its owner and user (1997, p. 142). The ability to perceive and recognise the aesthetic qualities inherent in the typical objects prized in the studiolo acted as 'proof' of one's civility (Thornton, 1997, p. 7). Thus, Renaissance scholars and those seeking accreditation to the educated elite surrounded themselves with precious and rare sculptures, books, objets d'art and paintings, believing that the presence of such objects in the confines of the academic interior conferred additional intellectual enrichment and cultural refinement.

However, the encroaching Age of Enlightenment with its preference for a more 'scientific' model of collection and display began to dissolve the concept of the studiolo as a singular space for the display of one's own collected artwork and artefacts. This age achieved the rise 
of 'cabinets of curiosity', rudimentary engagements with taxonomy and classification that academic art librarian D. Vanessa Kam argues represents a "prototype of an institutional hybrid that was simultaneously library and museum" (2001, p. 11). The development of classification standards along with the growth of the museum concept began to dominate the Renaissance fervour to collect and display objects purely for their capacity to "stimulate wonder or delight" (Rice, 2010, p. 12). Yet, the association of artwork with rooms dedicated to the intellectual enrichment of its inhabitants, and the quintessential interior associated with that activity, a library, has remained. As the accepted definition of libraries expanded to encompass greater and more egalitarian ambitions, the placement of artwork in such scholarly spheres has not abated, but rather achieved a lasting resonance and 'default' position.

\section{Contemporary literature associating artwork and academic libraries}

The engagement and appreciation of artwork in academic libraries is found in the policies of institutions which actively define the objectives of art programmes and the role that artwork should fill. The literature suggests that as libraries become more multidisciplinary and aim for an inclusive identity, the placing and impact of artwork comes to pre-eminence. An architect specialising in designing academic libraries, Geoffrey T. Freeman, proposes that academic libraries have always "held a central position as the heart of an institution" (2005, p. 1). It is their permanence and resolve in the face of threats of dissolution from digitised forces that maintains the value and relevance of the academic library as a "temple of scholarship" (p. 1). Freeman states:

\footnotetext{
"Whereas the Internet has tended to isolate people, the library, as a physical place, has done just the opposite. Within the institution, as a reinvigorated, dynamic learning resource, the library can once again become the centrepiece for establishing the intellectual community and scholarly enterprise" (2005, p. 3).
}

The idea that the presence of artwork in the academic library achieves a 'default' position because its integral function reaffirms the identity of the parent institution is argued by academic librarian and art administrator Kurt Kiefer, who considers that: 
"The role of an art collection on a campus is subtle: it exists to depict the university as an open-minded, comfortable-with-abstraction, respectful-of-its-history, and centre-of-the-community kind of place" (2006, p. 17).

Kiefer thus assigns the artwork of all institutions to homogenous ends, but it is important to distinguish displays of artwork in the academic library from alternative on-campus art exhibitions in designated gallery spaces or office art.

Academic librarian Lee Sorensen (1987) defines the artwork in academic libraries, or the 'library art gallery', as an accessible space for students, staff and other community members, which is not bound by gallery dictum, making it flexible for potential exhibitors. For Sorensen, the value of the academic library as a display space is that it requires little financial outlay in terms of curatorial and administrative requirements, compared to traditional exhibition spaces (p. 121). His idea that the role of the librarian expands with the inclusion of artwork into the library space is a novel consideration. Sorensen emphasises that an institution should ideally appoint specific administrators rather than librarians for the technical and administrative duties associated with arranging displays. The addition of curatorial responsibilities falls outside the remit of academic librarianship: for example the choice between selecting work from the institution's art collection or commissioning work; defining the artistic direction and focus; the choice of styles and mediums; whether to hang works and decide on permanent or temporary exhibitions, are all best done by those experienced in art curation. Sorensen argues that such a librarian-curator is ideally placed as an advisor with an overseeing role, although such a person "must often contribute personal time outside work hours" (p. 122-123). To achieve a culturally enriching art space within the library, Sorensen states:

"The most important aspect of having [artwork] in [a] library is the special atmosphere it creates. Students, faculty, staff members and visitors are welcome...to come face to face with original art. [The library] offers...a respite from the pressures of coursework and daily routine" (1987, p. 122).

Sorensen's key ideas are explored by Suzanna Simor (1991), an academic librarian and art coordinator. To ensure an institution is successful and effective in exhibiting art, Simor emphasises the need to define an art space within the library, where museum-quality lighting is used. Like Sorensen, she agrees that technical and support staff, rather than librarians, should handle curatorial, technical and administrative tasks. Simor stresses the importance of 
establishing the artistic direction and goals of the displays through articulated policies at the outset and to promote and publicise the artwork on display in a manner consistent with the nature of the specific library. Simor also emphasises the necessity of ensuring support from the parent institution, and secure funding to ensure the displays in libraries become "a powerful resource to inspire, delight, renew and refresh" (p. 139). The result is that like Sorensen, Simor declares that every person benefits from contact with high-quality art offered on display in academic libraries. For Simor, viewing artwork in academic libraries is "for many students, their first conscious exposure to art" (p. 137), and the presence of artwork is beyond a decorative addition: it embodies democratic goals. Simor states that "all [students] of an academic institution should have easy access to art, and art is a cultural prerogative" (p. 137).

Other researchers also argue that displaying artwork in academic libraries benefits students and staff by both soothing and stimulating their aesthetic senses, and by the latent effects of creativity through subconscious artistic appreciation (Dillon and Gardner, 2004, p. 2). Dillon and Gardner (2004) also agree with Simor's view that democratising the access to artwork in academic libraries acts to "stretch the mind and the senses" (p. 139) of viewers. They note that in their library, extending the:

\begin{abstract}
"Opportunity to enjoy art outside galleries by hanging art in our stacks... soothes and stimulates the minds of weary readers and computer lab users when they need it most...seeing a work of art with an appreciation that is born of being caught off guard by sheer beauty. Those moments of reflection and appreciation are something our patrons and our co-workers deserve" (2004, p. 2).
\end{abstract}

Simor and Dillon and Gardner's claim that academic library users have a definitive 'right' to view original artwork as they engage in intellectual pursuits is supported by Jo Cates. For Cates, the establishment of exhibition spaces in academic libraries "connects the artistic community the library supports" with its user population (2003, p. 57). Thus the library becomes a "visually stimulating space where no one sits in silence" (p. 57).

Academic librarians Carol Jinbo and Christopher Mehrens argue that students are affected by their environment, and benefit from the latent and active effects of exposure to original artworks, especially when they are geographically distant from museums and galleries (2007, p. 40). Jinbo and Mehrens state that the "scientific method is not the only means of acquiring 
knowledge, [as] viewing an artwork is an intuitive means of acquiring information" (p. 40), a position somewhat similar to the edifying effects of the Renaissance-age studiolo user. Jinbo and Mehrens' further assert that artwork in academic libraries serves a "multiplicity of goals" to support the traditional provision of "collections, services and environments that lead to intellectual discovery, creativity, and the exchange of ideas" (p. 41). They liken the academic library environment sans art as "much like a prison cell" (p. 41), with stark sterility denying human communication or interaction. Jinbo and Mehrens' conclusions, drawing on the disciplines of philosophy, fine art theory and anthropology, emphasise that exposure to artwork, especially for a population stymied by physical distance, serves ethical, aesthetic and creative functions - a multiplicity of goals that academic institutions consider integral to their educative responsibilities. This argument is supported by James Rettig, who argues for the inclusion of art in academic libraries, stating that the practice encourages a wide range of visitors to libraries and allows art education to take place, an educational purpose that "resonates with the library's academic mission" (2004, p. 5).

In addition to the above, recent research by Jill Cirasella and Miriam Deutch (2012, p. 2) finds that the display of artwork can be primarily practical as it aids the existing storage crises of institutions, a secondary function to notions of purely discretionary aesthetic improvement in the library environment. This practice is not without its dangers, as D. Vanessa Kam points out that libraries are not necessarily safe homes for artwork, stating:

"Many institutions struggle to maintain the resources to provide their collections with the necessary environmental controls (humidity and temperature), acid-free materials for processing, and archival storage containers" (2001, p. 10).

Kam reflects that housing artwork in spaces ill-designed for the ideal environmental requirements of art storage will "severely compromise [the] future availability [of the artwork] to users" (2001, p. 11). Notwithstanding the merits of Kam's argument, the intrinsic and extrinsic value assigned to the display of artwork, and the role it plays to add vitality to the academic library, is deemed to carry more weight than the inevitable risks of displaying artwork in any physical and publically accessible location (Simor, 1991, p. 139).

The expression of the extrinsic value of artwork is seen in Jinbo and Mehrens' consideration that "it [aesthetics in its traditional definition] expresses truth in terms of what is proper in thought (philosophy), action (ethics) and design (art)" (2007, p. 41). That is, people are 
affected and transformed by their physical environments - in this instance, the academic library. Like Thornton, Jinbo and Mehrens agree that deliberate exposure to artwork is valued for its edifying effects. They extend this frame of reference, proposing that artwork on display through passive and unaware observation encourages an academic institution's core goals to promote intellectual discovery, creativity and the exchange of ideas.

While hosting artwork in the academic library promotes the refinement, edification and civility embraced in the Renaissance studiolo, research suggests that librarians are faced with new challenges of curatorship. Academic librarian Jane Kemp (1994) surveyed librarians in small American liberal arts colleges to gauge the level of competence and confidence that librarians have with their expanding roles as curators of artwork displays. She concludes that the role of curator goes beyond traditional academic librarianship. Despite libraries managing art "due to longstanding, purposeful design" (p. 162), the transfer of caretaking responsibilities to them (often due to art museum and gallery closures or cutbacks) means that academic librarians adapt to roles they may not be prepared for. Kemp finds that the supervision and maintenance of artwork is frequently an 'add-on' to existing academic duties, regardless of whether the librarian is trained for or desirous of such responsibilities.

Kemp's results agree with both Sorensen and Simor's view that, in the absence of dedicated art staff, the successful exhibiting of artwork in academic libraries is dependent on the flexibility and willingness of librarians to take on a curatorial role. Furthermore, Kemp takes the position that librarians should be willing to embrace their changing roles and accept that "campus art collections [have] evolved from being considered mere furnishings to become an intrinsic component of the overall educational process" (p. 163). However, while democratic in intent and designated as a form of public good, the role of the librarian-curator can present problems. For example, Kam (2001) questioned from a curatorial perspective whether libraries should engage in the practice of acquiring and displaying artworks and art objects. She agrees with Kemp's argument that librarians lack adequate training to organize and preserve art objects, especially when decision making and assessment is relevant, as the curator's role is to "actively interpret or contextualize objects placed on display" (2001, p. 10). This falls beyond traditional librarianship, which, while expansive in its roles, does not usually include training in the interpretation of visual art material for public display (Brewer, 2011, p. 75). 
However, Kam also considers that "if it can be accepted that libraries are appropriate repositories for art objects, and librarians are deemed appropriate caretakers for such collections", the added value offered by libraries and librarians outweighs the services offered by other institutions and professionals (p. 12). Additionally, Kam refers to the relative scholarly independence of academic libraries, which collect material to meet wide ranging research needs, and therefore "are in a position to collect and exhibit more freely than their colleagues in museums and galleries" (p. 13). Kam posits that such broad collecting mandates and the purpose of academic institutions to foster creative and novel thinking creates opportunities because "libraries [which have art collections] have the potential to become sites for collecting and exhibiting art that...is not readily accepted by traditional or mainstream institutions" (p. 13).

However, there is a counter view that the liberal interpretations of display policy in academic libraries, where an emphasis is placed on exhibiting challenging or non-mainstream artwork, can lead to schisms of occupational identity. The ideological and practical divide between the occupational cultures of librarianship and curatorship is evident in the physical divisions of shared space. This argument, proposed by architect and social anthropologist Dennis Doxtater, asserts that the contemporary workplace is "primarily territorial in essence" (1990, p. 108). Thus, the academic library setting is 'territorialised' by the "use of signs of domination, dominance and hierarchy" (p. 116-117) and the introduction of curatorial involvement challenges the incumbents of that space: the academic librarians in their working roles. While the melding of the curator and librarian roles has been identified as successful in some examples (Cirasella and Deutsch, 2012, p. 15-16), the distance between the occupations is similarly identified as an inherently difficult one. For example, focusing specifically on the University of Virginia law library, Academic librarian Taylor Fitchett (2002) identifies the hidden 'ice-bergs' of censorship and curatorial sensitivity in the library-art exhibition environment. She provides insights into the complexity hiding beneath the surface of artwork displays in academic libraries.

In one case Fitchett describes how an African-American law student was insulted and offended by a painting which depicted, in the student's mind, the unfortunate history of slavery and servitude. Fitchett considers the strength of the student's criticisms and the powerful effects that art can evoke, noting that "it is hard to predict what people will find offensive" (p. 13), and states that choosing artwork that will have substantive and popular 
appeal is difficult. The integration of standards of quality, taste and appropriateness can be seen in the art theorist Margaret Wyszomirski's (1982) comments that open-ended definitions of taste bring charges of elitism, due to the subjective problem of identifying artistic merit. Wyszomirski's description of the tension between the "quest for excellence and the quest for quality" (p. 13-14) and the 'elitist' and the 'populist' is seen in Fitchett's narration of her experiences as a defender of displays in the library. For Fitchett, her curatorial responsibilities were considerable, and not just the notional role proposed by Sorensen.

Fitchett views the academic library environment as subject to the same sort of controversies that plague museums and galleries over their choice of content on display. This supports the idea that the academic library is a space for public art, which is similarly faced with criticism for its subjective nature, taste and appropriateness. The idea of democratising access to artwork, a major motive for exhibiting artwork in academic libraries, is found in public art theory, a sub-discipline of Art History. Generally, public art refers to artwork that can be accessed by the public and the term is typically used to refer to works in any medium that are created with the intention of being sited in a public place, outside the spaces and conventions of galleries and museums (Miles, 1997, p. 12). The purposes of public art, both to enrich civic culture by enhancing shared spaces and to act as a physical embodiment of a community's identity, are similar to an academic institution's reasons for displaying artwork. Accordingly, this discussion expands the notion of a public art space to include the academic library, consistent with the idea that public art is publically accessible - far from the outdated and limited notion of the 'object' in the plaza. This perspective is supported by Mark Wilsher's conception of contemporary public art as a "wider idea of a kind of art that takes publicness as its subject without necessarily needing to expose itself to the weather" $(2009, \mathrm{p}$. $331)$.

The relevance of public artwork to civic or institutional identity creation and affirmation is articulated by art commentator James Beech's view that:

"Public art can help to raise property values, provide a landmark for the visual branding of a city and raise the tone of a deprived city centre without ever entering into any public encounter" (2009, p. 329).

Similarly, for an academic institution, publically accessible (observable) artwork becomes a highly visible and attributable public relations tool to promote the status of its parent 
institution (Brewer, 2011, p. 75). Considering the academic library as a public place, however, is complex: while the parent institution caters primarily to staff and students, it usually has strong ties to the community and is often heavily funded by tax-paying citizens (Pirl, 2006, para. 1). Viewing the academic library as a wholly private space is similarly inadequate, as it denies the relationship the institution has with its community. The academic institution therefore hovers between the divides of private and public existence. Its art collection, frequently scattered across campuses, may be treated like public property if it is visually accessible by the public.

In writing of the public art 'audience', art commentator Malcolm Miles considers that there can be no all-inclusive concept of a "general public" who view certain artworks. Instead there is a "diversity of specified publics" for whom 'public art' in a defined location is created (1997, p. 84). His research does not take a traditional analysis, where public art centres around discourses of urban development, public right or might and civic issues of identity. Rather, Miles' findings bolster the exploration of the fixed academic library environment coexisting as a public art space. His novel view is supported by the public art consultant Sandra Liljenwall. Liljenwall investigates the motivations for public art collections in academic institutions in the US and establishes that if artwork situated in or around an academic institution is generally accessible to all, it is public art (2008, p. 9).

The sense of 'membership' into a specified 'public' that is assigned to a user of an academic library is seen in Freeman's declaration that the academic library:

"...is a place where people come together on levels and in ways that they might not in the residence hall, classroom, or off-campus location. Upon entering the library, the student becomes part of a larger community - a community that endows one with a greater sense of self and higher purpose" $(2005$, p. 6)

These perspectives reinforce the establishment of the academic library as a public place. Just as artwork in a public park is designed for users of that space, so too is artwork in the academic library setting designed for that member of the university's 'public' - either official in terms of student or staff status, or a visiting member of the general public.

However, while the artwork in academic libraries is a considered a valuable asset, it also incites criticism and division in its audiences. Public art is renowned for attracting critics from all levels of the community, each dissecting the skill of the artist against the presumed 
desires of the 'public' and the chosen allocation of public funds. Viewing artwork in academic libraries as public art thus opens new avenues for criticism. The academic library viewed as a public space is not the art-honorific sanctum of the museum or gallery, where opportunities to appreciate aesthetic refinement are consciously chosen; visitors to the academic library have artwork thrust upon them: it 'reaches' out to greet them. Considering Fitchett's suggestion that the role of librarian-curator is not for the faint hearted, academic librarians are also the unsuspecting viewer: art is similarly thrust upon them also.

This project is motivated both by the absence of research that explores how academic librarians perceive the artwork they are hosting and the developments in Art History and Information Studies discussed above. The themes addressed in the literature review are also incorporated into the research questions below. These topics include: the inferred effects of art in a learning environment; the institutional motivations for display in the academic library setting; the challenges faced by librarians as a result of their workplaces hosting artwork; a consideration of the academic library art as public art; and the difficulties between occupational cultures that arise as a result of meshing curatorial and librarian identities. The developed literature provides a base from which the central research questions are developed:

- Is it relevant for an academic library to display artwork?

- Is there a purpose for artwork in the academic library?

- What benefits, and pitfalls, are seen as a result of an academic library hosting artwork?

- Can academic libraries be public art spaces? 


\section{Methodology}

\section{Selection and description of the research site}

The University of Auckland is an example of an institution of higher learning which has built up a large valuable collection of artwork over a period of years primarily for the purposes of display. The history and development of the collection, its formal establishment in 1966 with the support of the then Vice-Chancellor Dr Kenneth Maidment and noted history Professor Keith Sinclair, and its current status is extensively covered in a thesis by Stephanie McKenzie (2006). The initial collection was intended to mirror Victoria University of Wellington's in scope. It would provide an addition to the university environment that was not already met in tuition or in the physical environment. In detailing the rich background of the University's collecting practices, McKenzie affirms the relevance and importance of the collection to the institution, its staff and students, the greater art community, and the role the University plays as a valuable patron to the commercial art market.

The collection acquired by the University is now centrally controlled by the University of Auckland Art Collection (established in 2006) which governs both from an official policy mandate and more immediate, less formal adjustable guidelines. The Art Collection includes valuable and original works by many critically acclaimed New Zealand and foreign artists and is held as a fine example of institutional collecting and as a significant national collection. The wealth of artwork, reflecting a wide variety of genres, mediums and scales, is located throughout the University's hallways, offices, outdoor spaces, and common areas, and demonstrates the institution's commitment to visually enhancing its spaces and fostering the arts community. The University's commitment to their collection can be seen in the regular acquisitions, continual support of artists with an affiliation to the institution, regularly updated guidelines for acquisition and commissions, and more recently with the development of the University of Auckland Art Collection application for mobile devices - a walking tour that identifies the location and key facts of artworks located in and around the grounds of the city campus.

The General Library is a rich case for investigation as it holds an impressive display of artwork alongside a dedicated public art exhibition space, Window. Window is located in the 
entranceway of the library complex. Although the artwork in the General Library is now centrally managed by the Art Collection, several works were originally purchased from small surpluses in the library's budget due to 'art-aware' former Chief Librarians, who wished to "liven up" the library's walls through art (McKenzie, 2006, p. 78). The General Library also hosts several works designed specifically for its space, and as such are 'immoveable' features of the library (McKenzie, 2006, p. 78). As a working building in the University, the General Library serves a quasi-ecumenical function: it is a central meeting point for users of all ages, background, faculties and subject interests. It is the largest of the university's 14 libraries and information commons areas and is centrally located at the heart of the city campus. The General Library comprises eight stories of shelving and study space, an entry foyer with an inbuilt exhibition gallery space (Window), and lecture theatres beneath. As suggested by its name, the General Library caters to a wide range of disciplines, including Arts, Business, Economics, Sciences and Languages. Students, academic and general staff rub shoulders with the general public, as there is no barrier on entry or for browsing the collections (University of Auckland Library, 2012).

\section{Theoretical framework}

This research project is a qualitative case study which uses aspects of ethnographical methodology to assess the nature of artwork in academic libraries from a variety of perspectives. The interdisciplinary theoretical framework includes incorporating data and relevant aspects of public art theory and of art curatorship referred to in the earlier literature review.

The data set includes semi-structured interviews with 11 interviewees, being seven academic librarians, three curators of the Window exhibition project and the Director for the Centre of Art Research. These interviewees assist in understanding the key issues associated with the display of artwork in the General Library. The interviews were open to all qualified librarians working in the General Library but especially to those who had an interest in artwork. This qualifier is intentional, as encouraging participants who have a genuine interest in artwork attracts those more likely to contribute meaningful and interesting data, as well as providing informed opinions about academic libraries as homes for artwork. 
This project adopts several measures to ensure that research is conducted in an ethical manner. The research received ethical approval from the Victoria University of Wellington Human Ethics Committee, and the project follows the University's ethical guidelines. This involves submitting a description of the research project, proof of institutional permission to use the research site and solicit participants and photographs, the sample questions to be asked in the interview, the Information Sheet to be presented to each interviewee prior to their interview, and the Participant Consent Form that each interviewee was required to sign before their interview (copies of these documents can be found in the Appendixes). Participants were informed that the recorded data they provided, and the transcriptions thereof, are to be securely stored against access by unauthorised persons for a period of two years, at which point all participant data will be destroyed. Participants were also informed that an electronic version of the completed research project may be published in academic journals or the findings presented at professional conferences. All interviewees had the option to withdraw their contribution before the end of data analysis (1 May 2013). No requests to withdraw data were received. In addition the participants were ensured confidentiality in order to solicit in-depth and unguarded responses.

\section{The observational framework}

Over a series of visits to the General Library I conducted observational analyses of the artwork on public display, but did not include works in private offices, staff areas of the library or elsewhere in the University, whether publically viewable or not. The "public display' qualifier included all artwork that any user of the General Library, affiliated or unaffiliated with the University, could freely view. The observations made included schedules of the physical distribution of the artwork throughout the library, the types of artwork on display, the concentration of particular styles, mediums and the details of their locations. The photographs of the artwork in the General Library were taken with the permission of the University Librarian on 11 May 2013.

\section{The interview framework}

I conducted interviews with librarians working in the General Library, the curators involved with the selection and maintenance of artwork in the Window exhibition space, and the Director of the Centre for Art Research (hereafter the 'Director'), who coordinates the 
representation and maintenance of the University's Art Collection. I approached the curators and Director separately for their respective interviews. I recorded and described these conversations in field notes and in transcriptions. The interviews lasted between 35 minutes and 1 hour in length. In addition to the formal interviews, I used follow-up unstructured methods including emailing and phone conversations as necessary to reinforce my understanding of the data, and to clarify some specific issues raised by participants. I taped and transcribed the interviews, and embedded observer comments in the transcribed text as I reviewed it to ensure the emphases made by the participant in the course of the interview were indicated.

The interviews were semi-structured and include the following kinds of questions for the librarians:

1. Do you feel the artwork in the library has a specific purpose; and if so, what is that purpose?

2. Are academic libraries appropriate places to display artwork; and if so, why?

3. Do you think artwork has an impact on the library environment; and if so, what is that impact?

4. Does the artwork have an effect on library users, or staff?

5. Do you think the library is an effective carer of its artwork?

6. What issues arise as a result of the library hosting artwork?

7. Do you think the artwork here is public art?

8. Would you like greater curatorial responsibility toward the artwork on display here?

9. What are your thoughts about the Window exhibition space?

10. Do you feel Window adds value to the academic library environment?

The curators of the Window project were asked more specific questions relating to their perceptions of the relationship between themselves, the gallery environment of Window, and to librarians and library management, as well as exploring the physical constraints that operate in hosting fixed, but temporary, art exhibitions. The Director was asked more specific questions relating to the governing mandate of the Art Collection, the policies in place for acquisition and collection management, and the history of the General Library's collection and arrangement of artwork. 
The purpose of these semi-structured interviews is to solicit personal and fruitful discussions. The questions listed above were used as a starting point for the participants to explore their thoughts on the artwork in the General Library, and to expand on the practice of displaying artwork in academic libraries more generally. The participants were guided to focus on particular aspects of the exhibits, but the aim of the interview portion of the research project is to obtain personalised insight into the issues associated with displaying artwork in an academic library setting.

\section{Data Analysis}

As I collected and analysed data from preliminary physical observations, further issues relevant to the project emerged, which informed the later interviews. Using the semistructured interview methods outlined above, I collected data from the participants and recorded recurrent themes. With the accumulation of data, I looked for similarities between my data set and the conclusions drawn by previous researchers in the literature.

The examination of the data used the established process of thematic analysis, a qualitative research methodology identified by Alan Bryman (1994, 2008). This approach was especially relevant due to the diffuse nature of the interview data collected for this project. All interviews were transcribed verbatim and subject to thematic analysis. This process involved considering the participant responses in relation to the key theoretical concepts and literature previously described.

Analysing the collected data involved identifying and arranging the recurring motifs and patterns emerging in the participants' interviews into categories of significance, a 'thematic' framework where the data is "sifted and sorted" (Bryman, 1994, p. 180). These categories were then amended to incorporate other novel emerging areas of interest, as well as linking the research data to the previous literature, the perceptual framework of the project, and research questions. Using this approach, all of the categories of significance were subsequently refined, ensuring that all relevant and meaningful themes are included in the eventual findings. This methodology ensures that the recurring motifs arising from the data persisted throughout the data collection process, and were strengthened by additional interviews with participants (to confirm answers) and in additional observational analyses. By 
analysing the content data and ordering and synthesising the reoccurring motifs through a process of ethnographic content analysis, six key themes emerged:

- the recognition of the importance of artwork in academic libraries;

- the informational qualities inherent in artwork and its suitability in a designated learning environment;

- the motivations for display in the academic library setting;

- the challenges of the academic library as an art space;

- a consideration of the academic library as a public art space;

- and a focus on the occupational divide evident in the Window exhibition space.

Several secondary themes emerged, such as the recommendations from the librarians for future improvement of the relationship between the library and the University's art body. These will be incorporated where possible. These themes are expanded to include comparisons with the relevant conclusions of previous literature, and also to advance those findings.

\section{The role of the researcher}

My role in this project was to take both objective and subjective interpretations of the data collected. As a post-graduate in Art History from Auckland, I have knowledge of and familiarity with the University's artwork and the General Library in particular, and my research background in public art theory was central to this research project. Due to my association with the General Library and existing relationships and contacts there, I was able to use the library as the case study for this research project.

In the initial observational part of the project, a subjective approach is used to document my personal opinions of the way the General Library displays its collection, because of the subjective nature of art appreciation. For example, the preferences for the hanging and displaying of artwork can vary significantly, as artwork is viewed through different frames of reference, awareness, qualities of personal taste and understanding. There are many opinions on whether a work should be hung above, below or at eye-level, for instance, as well as whether similar styles, sizes or types of work should be displayed together or apart. The 
overall evaluation of the curatorial effect is also a personal one, again due to the vagaries of taste.

In collecting data from participants during the interviews and subsequent follow-up discussions, I took an objective approach to guide the conversations during the semistructured format in order to collect meaningful and unbiased data.

\section{The possible research delimitations}

The delimitations of this research project are intentional: in selecting qualified academic librarians with an interest in art who volunteered to take part in an interview, instead of all workers of the General Library, the number of potential participants is reduced. Qualified academic librarians are more likely to have a grounded understanding of their role within the General Library environment, as well as practical experience working with the artwork displayed there. This criteria eliminates other workers in the General Library (such as IT or support staff) who might not have close contact with the artwork due to working away from the public areas featuring the displays.

Additionally, as a core focus of this research is to examine librarian perceptions toward the hosted artwork, the opinions of others working in the same environment will not provide the required data. Another intentional delimitation is the restriction of participants to the three core groupings: academic librarians, the curators of the Window exhibition project, and the Director for the Centre of Art Research. The choice not to interview student, staff or public users of the space is also consciously made. To conduct interviews with these wide-ranging populations requires substantial sampling methodology in order to establish representative groups. Also, as the General Library welcomes a wide variety of users, who are often transitory, it is difficult to identify those who can offer meaningful and enlightening contributions about the artwork on display in the library. No sampling methodology is applied to restrict the participants who supplied data for this research project, as this would unnecessarily extend the scope of this project beyond the recommended limits.

The delimitations of this project mentioned above highlight some limitations of the approach taken. One such limitation is tied to the perception that qualitative research is essentially descriptive and therefore not rigorous, and that it is too subjective and suggestive (Goulding, 
2002, p. 155). A further criticism is the lack of transparency in qualitative research, where the connection of a researcher to their conclusions is unclear. This section addresses these issues by identifying the reasons for choosing the observational and interview methods applied in this case, and how the data was analysed. The use of thematic analysis means that the most prominent and recurring issues emerging from the interviews are used to consolidate the data, and in turn draw a portrait of the participant responses that effectively answer the initial research questions. This thematic analysis process requires the 'thought processes' of the researcher to be clearly identified through supporting primary source evidence, thereby establishing more transparent associations between concepts. 


\section{Results}

\section{Analyses of observational data}

I observed the types of artwork, their distribution and visual accessibility to evaluate the overall impression created. The Entranceway/Foyer area of the General Library features two distinctly different types of art: the alternating contemporary exhibitions of Window, and the fixed sculpture of Richard Killeen in the form of 17 lacquered objects in Red Insects, Blue Triangles (1980). The contrast in these forms is noticeable, as each represents a different medium and artistic intent. Window's short descriptive label invites ambiguity, whereas Killeen's contribution features a full explanation and interpretation. Killeen's work dominates Window, as the nature of the library complex, with its large expanses of open light, causes Red Insects, Blue Triangles to reflect on the glass vitrine of Window. Yet, despite these two artworks apparently engaging in a 'stand off' (as each is affixed to the library's side walls), they in fact welcome the visitor to the library and to the lecture theatres below by promising further visual and intellectual stimulation above in the library, or below in the theatres. These theatres also feature artwork in the form of Maori spiral relief designs commissioned by the artists Fred and Brett Graham.

The Ground Floor area of the General Library features both a localised collection, and more generalised artworks. In creating the feeling of a meeting area, recalling Marae design, several Maori carvings are fixed to the Maori and Pacifica area. These carvings are also supported by several tukutuku panels, and further into the Ground Floor area there are other artworks, especially the painting Te Kaleve by Fara Pikiti (1994) which features a young Pacifica man cutting coconuts in a tree. These works establish this level of the library as the site for the Maori and Pacifica collections in the library. The Ground Floor also features more atypical artworks, such as Denys Watkins' Encounter of the Third Kind (2008), behind the central librarian's desk. This painting illustrates a boy watering a garden (and is suggestive of other types of watering). The visibility of the artworks in the Ground Floor area is somewhat limited. Due to the volume of library users entering the library, the artwork is confined to the safer and less-used corners of this area and away from potential accidental human encounters. 
One such 'safe' area on this floor is the Special Collections Room, a small publicallyaccessible space with its own opening hours. This room primarily caters to researchers and holds the University's precious and prized scholarly materials. Alongside an elegant desk and chairs (which cultivate the 'reading room' experience), the room features small sculpted busts of a marble Dante (artist unknown, n.d., which is apt to don certain festive hats), and of Anthony Stones' bronze vision of (artist) Colin John McCahon (n.d.). The room also features elegant framed works, noticeably Dick Frizzell's South Side Dansey's Pass (1992), a wistful lithograph of a mountainous landscape. The Special Collections Room recalls the cloistered scholarly cell-environment of the Renaissance studiolo, and its artwork exemplifies the 'hidden-in-public' nature of some institutional art - where sophisticated and witty works such as Nigel Brown's woodcut print of Song to a Fern (1986) and Nicole Freeman's selfexplanatory The Lizard King (1988) are 'found' by fortunate users.

The First Floor, in conjunction with the Mezzanine Floor, present users of the General Library with a quasi-gallery experience. These two floors display much of the library's artwork collection, including work especially designed for this space during its substantial remodelling in 2002. The effect of a grand gallery space is reinforced by Selwyn Muru's He mihi ki nga Wairua Kaitiaki o te Whenua (1997), a vast mural stretching across a back wall of the First Floor space which can be seen from multiple angles and also from the Mezzanine Floor. Muru's artwork dominates the space, and its purchase in 1997 (in part from the General Library's funds) was commissioned especially for this location. Although there is no prevailing theme in the artwork between these levels of the library (apart from the Art Collection's acquisition mandate to collect artists affiliated with the University), the artwork is cerebral and intellectual. It reflects both the seriousness of its scholarly environment, yet subtly pokes humour at this self-reverence, like the inclusion of Robin White's Sam Hunt, Bottle Creek (1970) - Sam Hunt is a notable New Zealand poet. The cerebral element emphasising 'mind work' is suggested with the placement of two head-specific artworks. Sarah Munro's Socket (2003) is a highly engineered large-scale work featuring a man's head in oils digitally printed onto shaped polyester foam with a fibreglass shell, and Elizabeth Thompson's intaglio print titled Manakau Heads (1987), features an abstracted head, moving from a cliff top. The wider world is expressed by the Mezzanine Floor's 'hidden' sculpture a re-imagined and flattened globe, fittingly located outside the library's map room, titled The Known World (English Version) by Ruth Watson (1991). 
These two levels also host a range of mediums and sizes, some of which fit easily into the digital furniture of the library, for example the range of framed prints above a row of computers on the First Floor. The First Floor also displays a curiously risqué artwork, Rohan Wealleans' Blade Healers (2008), an acrylic on canvas wall hanging that features a subtly explicit grouping of nude women. Its semi-pointillist style and the inclusion of extra materials in the forms of rocks make this a bold choice for a publically-accessible library. The artwork is especially vulnerable to passersby, yet its placement in the library (against a wall and compressed by desks) effectively removes some of the work's power to amaze or shock.

The First Floor also features less salacious artwork, in the form of calming landscapes (such as Irene O'Neill's Matapihi, 1966), and still lives. In carrying most of the library's artwork, these two floors host some of New Zealand's most highly-regarded artists, including Don Binney (Kawaupaku Te Henga, 1967), and Pat Hanly (Inside the Garden, 1968). The display of artwork across these levels, often at or below eye-level and within easy reach, heightens the vulnerability of the artwork (to accidental or malicious damage), but provides the highest visibility within the library building. The majority of works here feature at the least name and date labels, usually at an easily readable height, and the distribution of the artwork across the First and Mezzanine Floors is even, with no concentrations that could potentially interrupt serious study. Instead, the effect of the artwork and the semi-hidden displays offer multiple points of visibility, and seem to play 'peek-a-boo' with the unsuspecting library user.

However, the dedicated curation of a gallery-style art experience ends at the Mezzanine Floor. The Second Floor has no artwork displayed and the Third, Fourth, Fifth and Sixth Floors of the General Library are far more conservative, each feature only one work, except for the Fourth which has two. The reason for this lack of display in contrast to the veritable wealth presented in the First and Mezzanine Floors is due largely to both the building's design, and the needs of the library. The First and Mezzanine Floors feature lofty walls, ideal for display, but as the General Library rises in height, the effect of its windows (which 'wraparound' the building) severely restricts the amount of internal walls for display purposes. The necessary shelving units holding each floor's printed material also limits the amount of artwork that can be displayed there. Some levels, such as the Third Floor (home to Asian Language material) have a reflective theme - in this instance, I. Njomen Gerebig's painting of Rice Planting and Harvesting (n.d.) featuring the rice paddy fields found in many Asian countries. Similarly, reflecting the content of the floor through the visual medium, the Fourth 
Floor (French National Language and Literatures) features a work showing a New ZealandFrench connection in Russell Jackson's 1826 The French in the Bay of Islands (1994), the title of which is fortunately inscribed (the title card is missing). The Sixth Floor features an intriguing and witty work, Liz Maw's Sirens (2009), a painting of an imagined female-led Viking-style vessel. The suggestion that the shields held by the 'sirens' might be easily misread as breasts was suggested by a number of library users as I carried out these observations - and indeed, Sirens requires a second glance to be sure of its exact content.

The stairwells of the General Library add aesthetic appreciation along with a safe passage and possible athletic activity for their users. The central landings of the stairwells, rising from the Ground to the Sixth Floors, feature a uniformly large expanse of wall, perfect for display purposes. The stairwells offer a highly visible location for the library's artwork, especially on the lower floors which are in constant use. As the collection of the library tends to take on a certain degree of permanence, the artwork of the stairwells coupled with Window, provide the library space with a much-needed opportunity for rotation and refreshment. Currently the stairwells display a total of 12 framed silkscreen pairs of prints by a range of New Zealand and international artists from 2008, all acquired by the Art Collection in 2010. These prints are untitled, yet each pair, some of which are incongruously matched, offer a sharp snap of visual stimulation that makes each floor instantly recognisable on repeat visits to the library. This is seen, for example, in the stairwell between the Ground and First Floors which contrasts New Zealand artist Saskia Leek's Untitled (2008), a silkscreen print depicting abstracted and faded colour blocks against the playful and bold, graphically-inspired design of Swiss artist John Armleder's Untitled (2008).

While attempts are made to limit the damaging effects of direct light exposure to the artwork throughout the rest of the library (as wherever possible, the artwork is hung away from a direct light-providing source); this is not the case in the stairwells. While the financial value of the stairwell works is considerably less than those in the General Library, they should not be left to the ravages of fluctuating and impactful sunlight. The ongoing conservation of all the General Library's artworks is also a concern, as several show signs of wear and tear, and in the case of one artwork, Helen Sandall's Enlargement from the Book of Hours (1969), an over painted print enlargement onto board, there is physical damage. Sandall's work has worn away and torn from its base, and faces future damage due to its location in a path of direct sunlight on the Fifth Floor. However, while some artworks could benefit from more 
judicious arrangement and placement to allow greater and more visibility, and some appear slightly askew, overall, the condition of the artwork in general is good, given the necessary caveat that the General Library is a building in constant, high-level use.

In terms of the choice of artwork the General Library exhibits a comprehensive and impressive selection of artists, mediums, scales and aesthetics. The introduction of more sculpture into the library would have a significant impact, and reflect a style of art that is somewhat neglected. For example the inclusion of Michael Parekowhai's frequently-sited life-size bronze sculpture, Kapa Haka (2008), to the General Library from its current location outside the Barracks Wall, would be a suitable future feature. This work, of an assertive security guard in defensive pose, has been shifted several times throughout the University (due in part to student hijinks and the predilection for the sculpture to don garments), frequently causes passersby to mistake the sculptured man for a real person (reinforcing the power of art), and the presence of added 'security' (in proxy form) to the library would help protect the artwork already held there, if only symbolically. 


\section{Physical distribution and location of artwork}

The table below identifies the location and distribution of public art in the General Library as at May 2013. The table also identifies the proportion of the University of Auckland Art Collection that is publically displayed in the General Library.

\begin{tabular}{|l|c|}
\hline $\begin{array}{l}\text { Location of publically visible artwork in the General } \\
\text { Library }\end{array}$ & $\begin{array}{l}\text { Distribution of } \\
\text { artwork on floors }\end{array}$ \\
\hline Entranceway/Foyer & 2 \\
\hline Ground Floor (including cultural carvings and panels) & 15 \\
\hline Special Collections Room & 7 \\
\hline First Floor & 7 \\
\hline Mezzanine Floor & 0 \\
\hline Second Floor & 1 \\
\hline Third Floor & 2 \\
\hline Fourth Floor & 1 \\
\hline Fifth Floor & 1 \\
\hline Sixth Floor & 12 \\
\hline Stairwells & 62 \\
\hline $\begin{array}{l}\text { Total number of artworks on public display in the } \\
\text { General Library }\end{array}$ & 1300 \\
\hline $\begin{array}{l}\text { Total number of artworks in the Art Collection } \\
\text { (approx.) }\end{array}$ & $4.7 \%$ \\
\hline $\begin{array}{l}\text { Proportion of the Art Collection on public display in the } \\
\text { General Library }\end{array}$ & \\
\hline
\end{tabular}




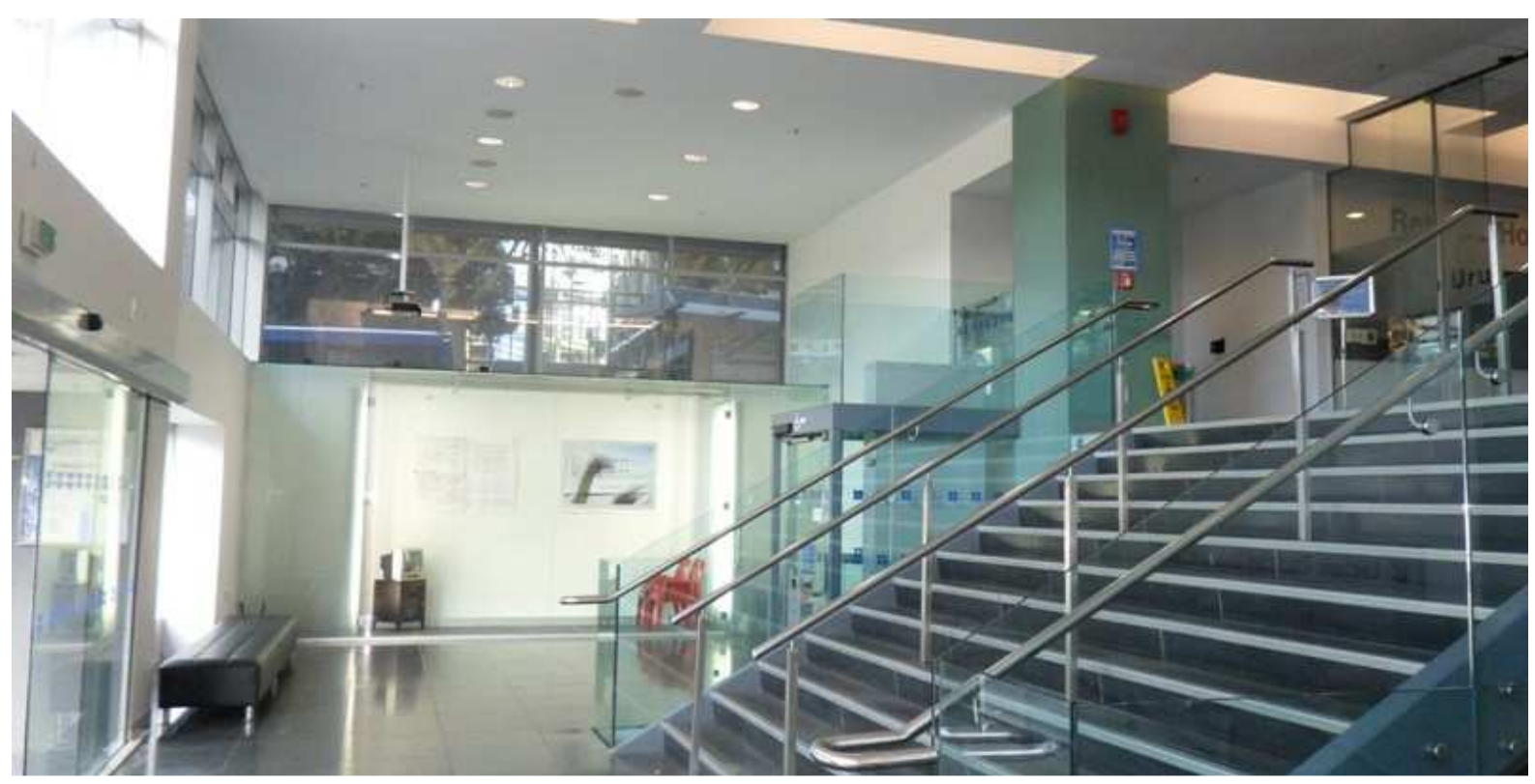

1. Placement of Window (showing Radio Strainer by Alys Longley and Jeffrey Holdaway, May 2013), General Library entranceway

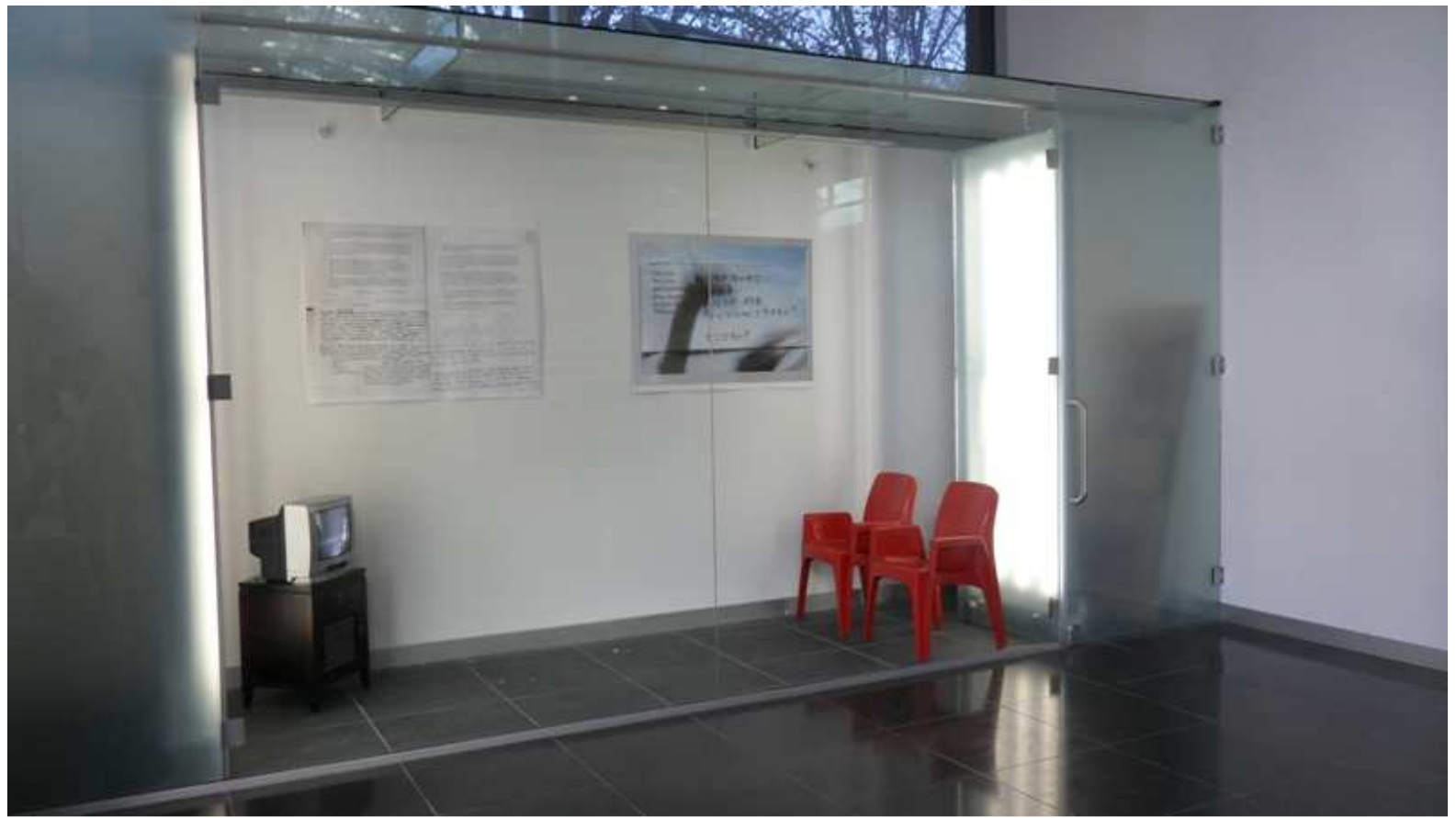

2. Close-up of Window (showing Radio Strainer by Alys Longley and Jeffrey Holdaway, May 2013), General Library entranceway 


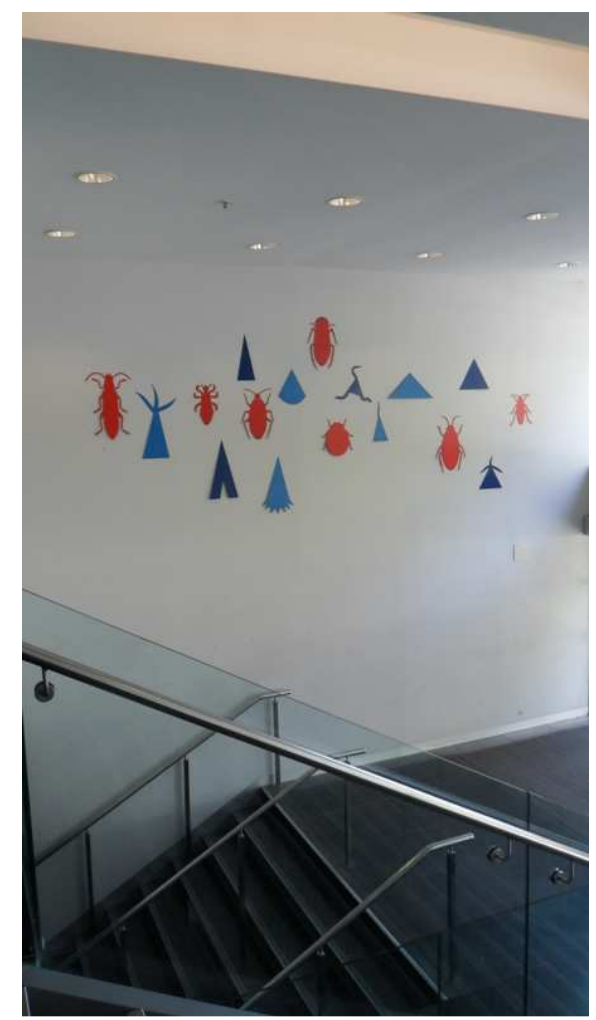

3. Red Insects, Blue Triangles by Richard Killeen (1980), General Library entranceway (seen from library doors)

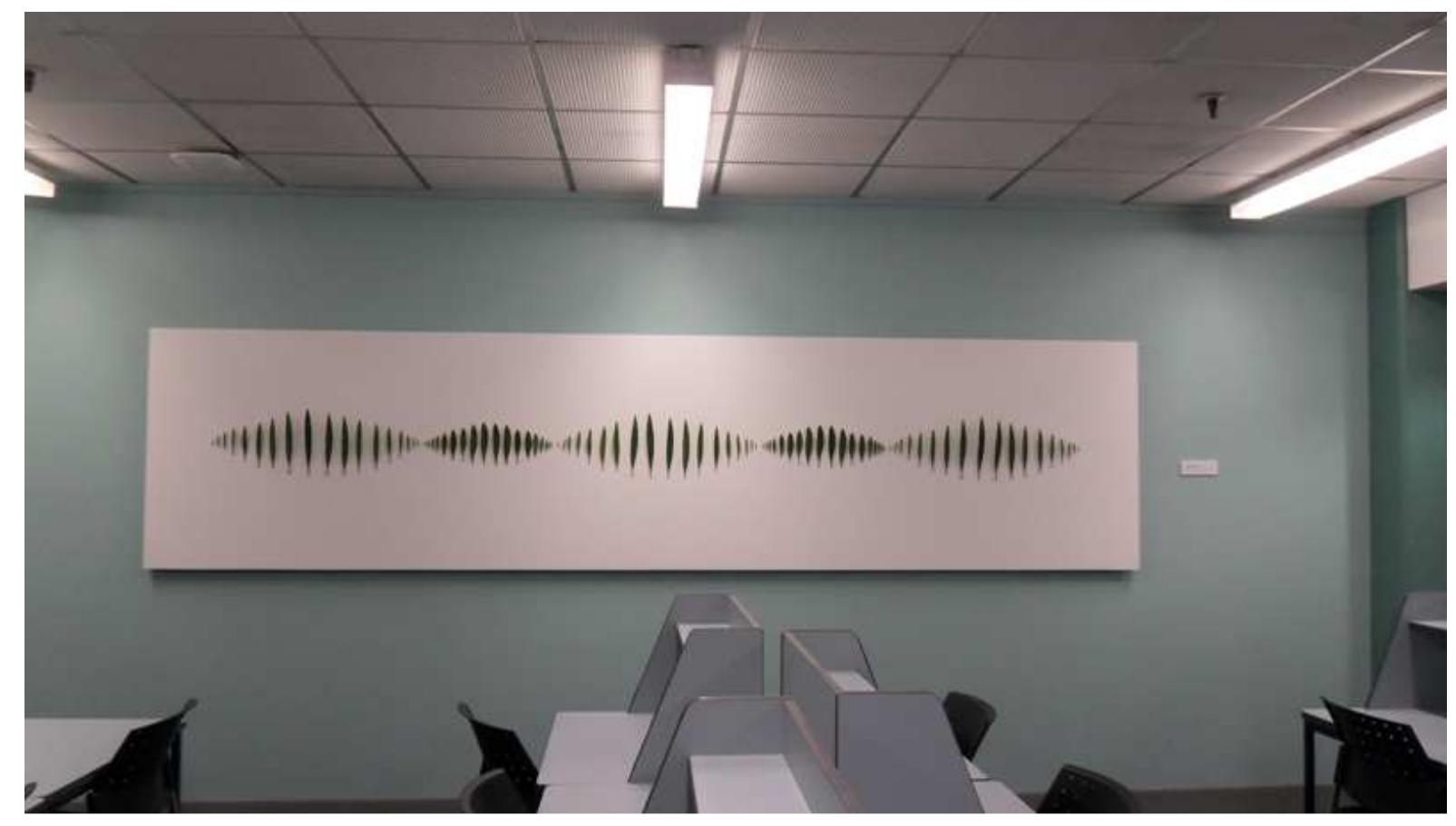

4. Sonic Panorama by Elizabeth Thomson (2002), Ground Floor, General Library 


\section{Analyses of interview data}

The data collected from the interviews have recurrent themes which bear direct connections with those from the Art History and Information Studies literature. It also raises novel considerations of the academic library as an art space, and suggests avenues for future research. The themes mentioned above have been analysed in separate discussion sections as follows:

I. the recognition of the importance of artwork in academic libraries;

II. the informational qualities inherent in artwork and its suitability in a designated learning environment;

III. the motivations for display in the academic library setting;

IV. the challenges of the academic library as an art space;

V. a consideration of the academic library as a public art space;

VI. and a focus on the occupational divide evident in the Window exhibition space. 


\section{Valuing artwork in the academic library setting}

The interviewees unanimously support the display of artwork in the General Library specifically, and for academic libraries more generally. The importance of artwork to the interviewees was expressed in a range of positive and enthusiastic opinions. These span from personal critiques to abstract and theoretical thoughts on the role of artwork in the workspace, and the impacts art has on its environment and users. That artwork is an opportunity to culturally and visually enrich the physical environment is acknowledged by the interviewees as highly relevant to the General Library. The importance of artwork in the academic library setting is prized by the librarians who work alongside it as well as by the curators of the Window space, who emphasise the significance of relational aesthetics. From the librarians' perspective, one states that the artwork "breaks the functionality and monotony of an otherwise purely functional, institutional building", where artwork heightens the eponymous 'generality' of the building.

The librarians interviewed demonstrate a strong fondness that develops towards the permanent displays in the General Library. Given that several of the artworks are designed especially for the General Library, and as such are 'immovable icons', the depth of attachment held by several long-serving librarians for them attests the suitability of the chosen works, and the affection of the staff members for the workplace over time. Three of the librarians speak of long-placed artwork, especially those near their work areas, becoming "old friends" to them. One librarian refers to the 'fight' to keep a much-admired painting in $s i t u$, in spite of its scheduled relocation during renovations in the library. The crux of the argument lies with the perception of due ownership: the artwork has become part of that section of the library's identity. The librarian managed to keep the artwork in its original placing with the challenge: "it's our painting - and we like it". These views add credence to Liljenwall's (2008, p. 14-15) suggestion that over time, permanently-sited artwork becomes a 'trade mark' for an institution. Although Liljenwall was speaking about externally-sited institutional public art, the interviewees in this case provide evidence for the importance of artwork in the working environment, and the value it holds as a physical place marker. The significance of the cultural displays in the General Library is also highlighted by a number of librarians, including one who stressed how the artwork, carvings and panels in the Maori and Pacifica section of the library create a supportive and responsive environment. The librarian 
thought that the presence of the tukutuku panels and carvings work to "localise the library", and that "it definitely has a specific effect on me working", adding:

"If I'm down in the Maori and Pacifica collection, even though I've seen them a million times before, I always gaze at the tukutuku panels or the carvings, and I feel a sense of belonging - to the library, and a greater connection to my culture. I feel there is a relationship set up through those pieces that is being communicated when I look at them."

Another librarian with an interest in the library's indigenous cultural perspective emphasises the 'stories' that are intrinsically tied to the artwork, and how such art objects take on a special cultural resonance with their placement. The value of the artwork in the Maori and Pacifica area, in this librarian's view, goes beyond monetary consideration as the works which were specifically commissioned for the space act as 'guardians' of the teachings held in the objects and materials of the collection, as well as the people who sit and study there. The librarian emphasises how the carvings and tukutuku panels may go some way to redress possible 'library anxiety', where users feel intimidated by the library and cannot function effectively in the space, a concept that Constance A. Mellon argues has special relevance in considerations of the academic library (1986, p. 162). The librarian interviewed expresses the idea that library anxiety, where feelings of inadequacy and inability are felt, could be higher amongst the underrepresented groups in the university community, including those who identify with Maori and Pacifica ethnicities. The influence of the physical library environment on minority groups in the university community is upheld by the investigative research of Sharon Elteto, Rose M. Jackson, and Adriene Lim (2008) into the racial differences amongst library users. The authors' central claim, of a library's responsibility to support the unique challenges faced by such groups, is similarly found in the response of another librarian who suggests that the placement of additional Maori and Pacifica artwork throughout the library would:

"Help our people feel more relaxed in this environment, where the stories and the 'chill' element of our space here could be carried through. The relaxed atmosphere we try to create here provides an element of homeliness, a relaxed space."

The librarian emphasises that "removing the barriers to the library" through the display of Maori and Pacifica art would have a flow-on effect to "warm" the rest of the library, especially during exam time where: 
"The amount of energy that comes through here is absolutely amazing: you can cut the tensions with a knife, and having tukutuku panels that students can rest against, artwork they can touch, may reduce their stress levels and help them to relax".

The ability of artwork to add vitality to an academic library, a key theme in the existing literature, is also emphasised by the librarians of the General Library. One claims the presence of artwork was significant as it:

"Brings an important vitality, and makes the place more comforting, more aesthetically nice to be in as it goes beyond just the collections of books and study tables to be an interesting space".

Other librarians support this view, with one stressing how the presence of artwork in the General Library "steps it out from the ordinary a bit". These opinions are further substantiated by the views of other interviewees, who emphasise their deep and personal enjoyment of the artwork around their working spaces. One librarian mentions how a screen print located in the stairwell (Untitled by Tom Kreisler, 2008, a sketch of an apartment block encased in a condom) always "makes me giggle like a teenager - even though I see it however many times a day - and I should know better!" Similarly, another emphasises the importance of being around beauty, saying:

"I truly believe that the environment has a huge influence on work and productivity, and that the artwork here has an effect on the users, and staff. I believe beauty, as in the beautiful artwork here, around us certainly contributes to productivity, because it brings these positive vibes."

This idea, of the transfer of idealised concepts of beauty in physical objects to viewers of such objects was a core belief of Renaissance scholars in their studioli, and still carries weight. Further extending the associations of beauty and productivity, the librarian adds:

"As [being around] beautiful things brings positive vibes, seeing the artwork gives you a few minutes or so of a positive visual break, which means you can return to your work refreshed and inspired, and do better work".

Similarly, another librarian thinks that visual material "subconsciously lifts people", as peripherally stimulating things work to break the "functionality and monotony of an institutional building such as this space". The artwork is also attributed to raising student 
awareness of the diversity of subjects that are taught at the University. For example, one participant notes that the school of fine arts, Elam, is a fair distance from the General Library but representing its visual art and artists in the central venue is a way to emphasise the possibility of academic worlds beyond the students' own. The librarian elaborates that:

"People come here pretty much focussed only on what they have to do and study, their minds are set into their various disciplines. Being exposed to the artwork here just creates a subtle awareness that there is another world beyond their immediate focus". 


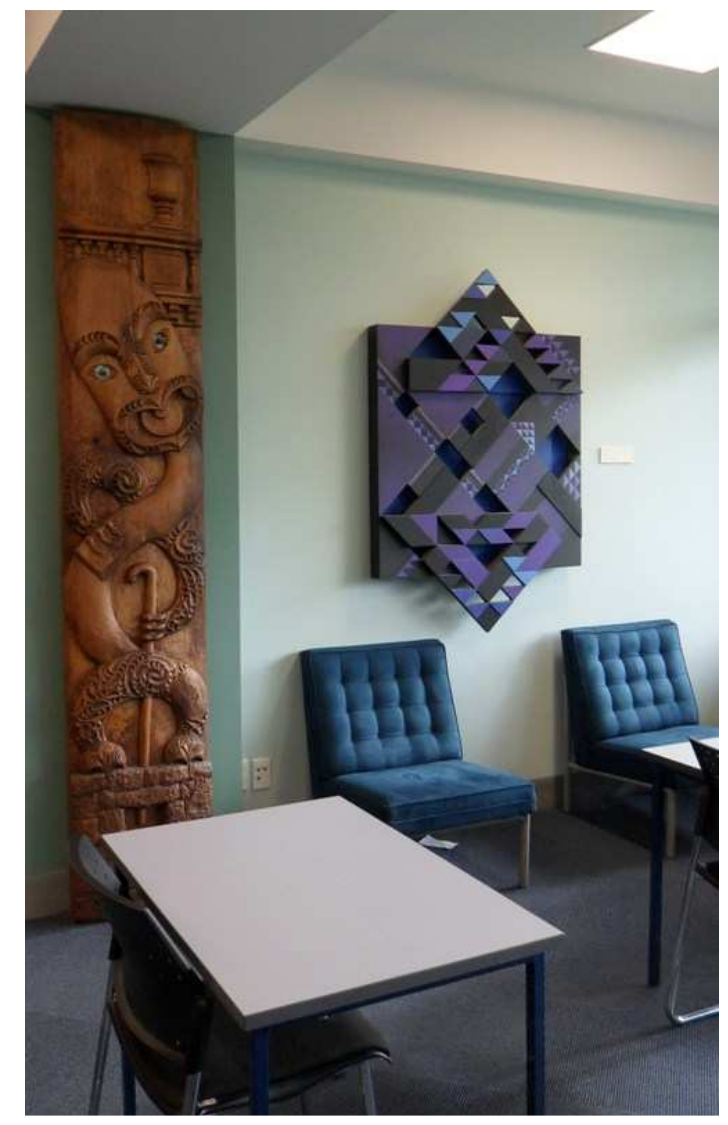

5. Carved Maori panel (left) and Niho by Jody Walters (n.d.), Ground Floor, General Library

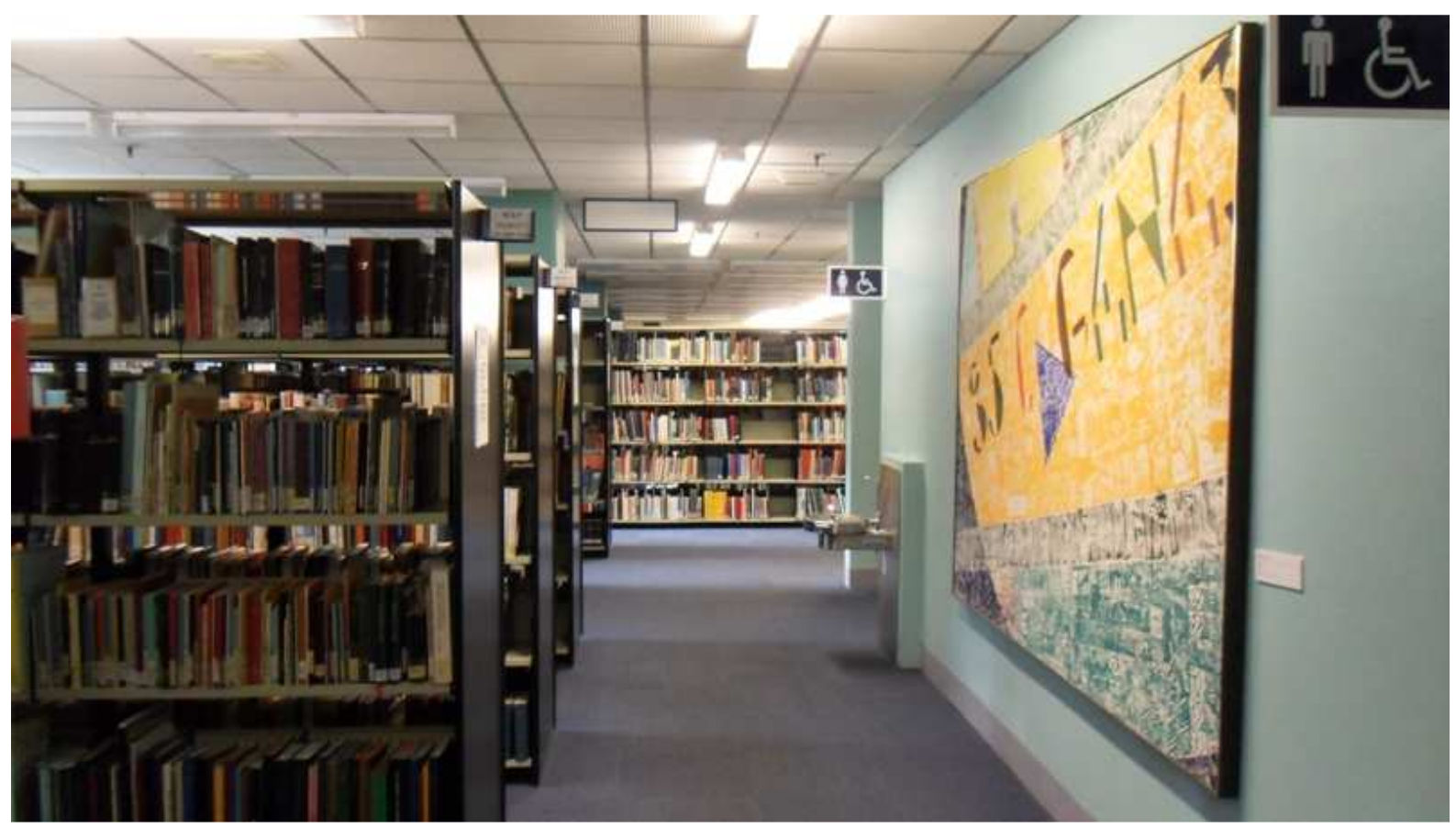

6. 35/35 by Phillip Trusttum (1976), Ground Floor, General Library 


\section{Seeing artwork as information}

Introducing users to others areas of interest beyond their own studies is clearly identified in the interviews as a central motivation for displaying artwork in the General Library. The interview data strongly supports the existing literature, which holds that the informational and educative value of artwork is essential to its placement in the academic library setting. The strength of these opinions outweigh the idea that artwork fulfils only a decorative role. The interviewees acknowledge that the artwork in the library space has absorbing and significant enlightening and scholastic functions. This personalised perspective is also formally mandated in the acquisition and commission policy of the Art Collection, the primary objectives of which are to "demonstrate the University's continual commitment to the study, patronage and advancement of the visual arts" (The University of Auckland, 2012). The collection has an important role to "enable research on the visual arts and support the teaching programmes [of the University]", which is manifested in the displays of artwork in the General Library (The University of Auckland, 2012). These guidelines for the display and purpose of the Art Collection are similar to policies from other national and international academic institutions.

Academic libraries, with their educational purposes and research output, are supported by the previous literature as a significant and suitable home for an institution's prized art collection. Kam's argument that:

"Libraries...are effective repositories for art objects, especially if the objects are part of a larger collection with qualities that invite scholarly study and research," (2001, p. 13)

is unanimously acknowledged and affirmed by all interviewees as a significant driver for artwork in the General Library. One contributes that as the General Library and academic libraries in general act as a tangible and highly visible display of the "serious research function" of the institution, the placement of artwork in such a space is highly relevant. This librarian expresses the view that artwork is integral to academic libraries because of "natural" associations between art and education. The role of artwork providing its own intrinsic value as a useable and useful academic resource in the library is also acknowledged by another librarian, who argues that: 
"Art is definitely a form of information - the saying that 'a picture paints a thousand words' is so true, and that the information of the picture is conveyed to an audience. So, as an information repository, alongside all the other materials and resources we collect for their informational value to our users, this academic library is an absolutely fitting home for art".

This idea, that the contents of an academic library (the artwork) and its description (a place for scholarly research), are fundamentally linked in purpose, to create the identity of a place of higher education reinforces the importance of artwork in academic libraries. In support of this analogy, one librarian states that the presence of "artwork can signal the work of higher, elevated minds and that is what we here in the library cater to". This refers to the responsive relationship between academic research, notions of intelligence, and creativity. The cultivated identity of the academic library as the specialised home of higher thought and education is supported by the presence of artwork: it fundamentally affirms both the cultural awareness of the host institution, and the meaningful and unique learning opportunity for users of the space. Thus, the artwork responds to its setting and enhances it, as the setting enhances the physical art object and imbues it with greater relevance as an information resource.

Such learning opportunities, considered inherent in the artwork itself are also declared by another librarian as "core to the duty and responsibility" of the library: to provide an educating environment through a range of resources. This is also the opinion of others interviewed, for whom the formal characterisation of academic libraries, and libraries in general as places where information is imparted, should reflect multiple sources of knowledge. The association of artwork with a significant, if latent, educative function is identified by several librarians interviewed. It supports Jinbo and Mehrens' argument that artwork in the academic library serves a "multiplicity of [possible] goals" (2007, p. 41). One interviewee emphasises that academic libraries must have a clearly defined mission to cater for the learning styles of its many users. Such learning styles could encompass "virtual, visual, kinaesthetic, or aural" forms. This librarian's view is particularly pertinent given that the General Library has a comprehensive mandate to service the needs of students and staff from a range of academic disciplines, and by extension, a range of differing learning style inclinations and preferences.

Another librarian interviewed examines the informational significance of the artwork in its setting with special reference to the Maori and Pacifica area. The specially designed carvings 
and tukutuku panels create a recognisable identity for the Maori and Pacifica materials located there, and the spaces within the fibres and carved wood are prized for the stories held in their physical form. For this librarian, these cultural material objects located amongst written texts take on important roles as information resources in themselves as "they hold the knowledge, there are teachings provided in those materials". She further notes that from an indigenous cultural perspective, these cultural art objects:

"Create a push, or an incentive to be more responsive to the specific needs of Maori and Pacifica students, and also because it so obviously represents our cultures, it might invite other people to learn more about our people and our stories. The artwork keeps the relationships flowing back and forth, and from that comes learning and education".

However, while the artwork ideally stimulates and creates an educative experience for the library users, the interviewees also emphasise the relative "invisibility" of the displays within the General Library, for example one librarian comments that:

"Those who are more inclined to notice their surroundings will appreciate the art we [librarians] do - but for some, they might not see it at all, even if they are sitting right beneath it".

The majority of interviewees express the opinion that the artwork in the General Library has a "stumble-upon" quality: it is found, rather than explicitly sought out, and as such, its ability as a useful information resource may be known only to a minority of art-conscious or artknowledgeable users. The Director and manager of the Art Collection comments that "while my expectation is that if art is all around you, then you will notice it, but you have to be realistic in this assumption: we are not all visual people." Notwithstanding these comments, the Art Collection is designed to enrich the institution's cultural environment - a visually stimulating component that supplements the other cultural activities like musical performances and theatrical productions to enhance the cultural life of the institution for its users. One librarian emphasises that the significance of 'critical thinking', a core concept of tertiary education, must be considered in evaluating whether artwork can be educative. The librarian declares that as universities are:

"Supposed to cater to enlightened individuals, it is our responsibility to offer resources that will give them an intellectual challenge. Even if students don't consciously notice the paintings here, it doesn't mean that we should get rid of 
them: not all the users are blind to their surroundings, and having artwork here has... a subconscious and significant role that supports the idea of the library being a place for serious research, serious thinking, and creative output." 


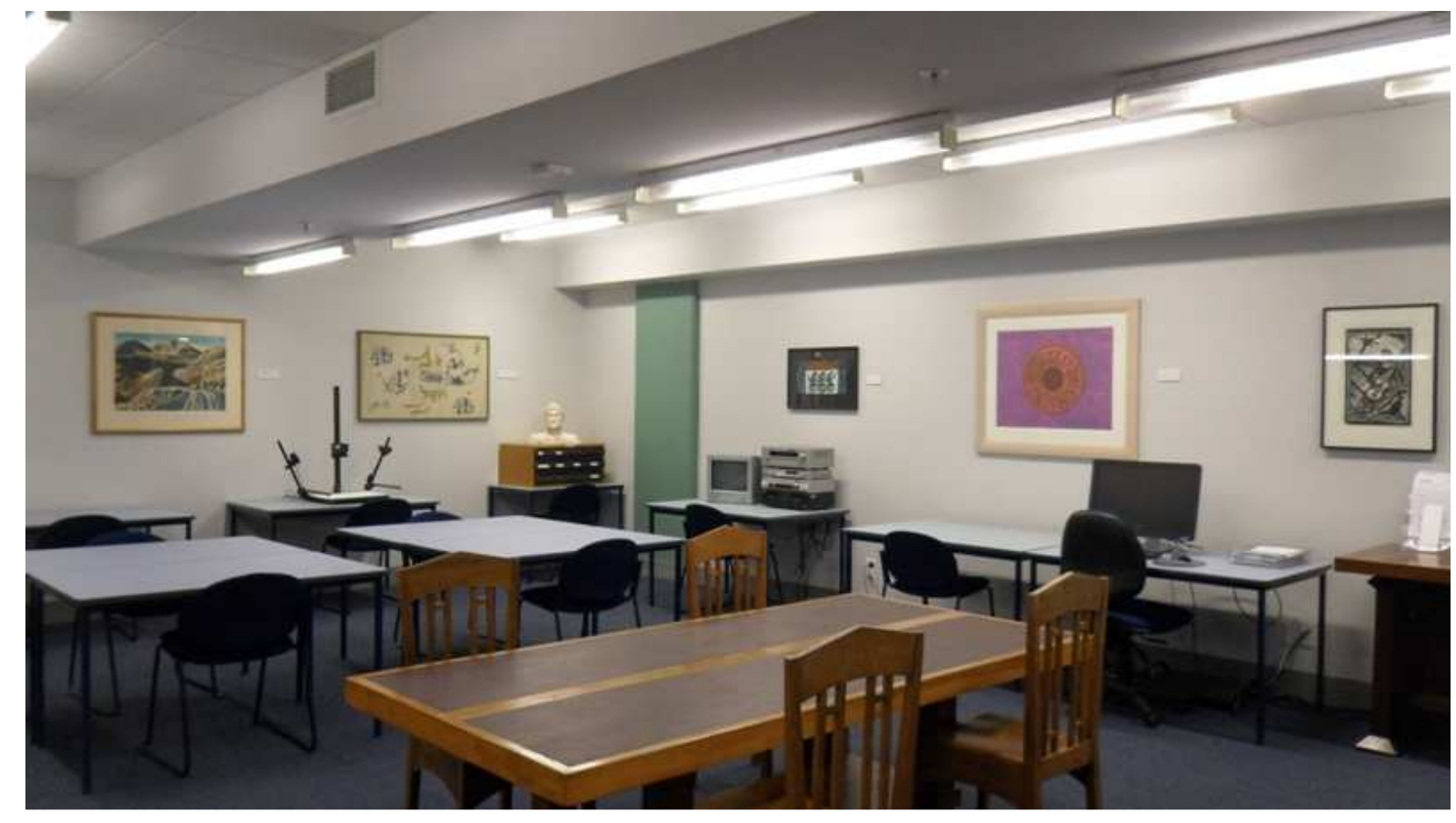

7. Artwork in the Special Collections Room, Ground Floor, General Library

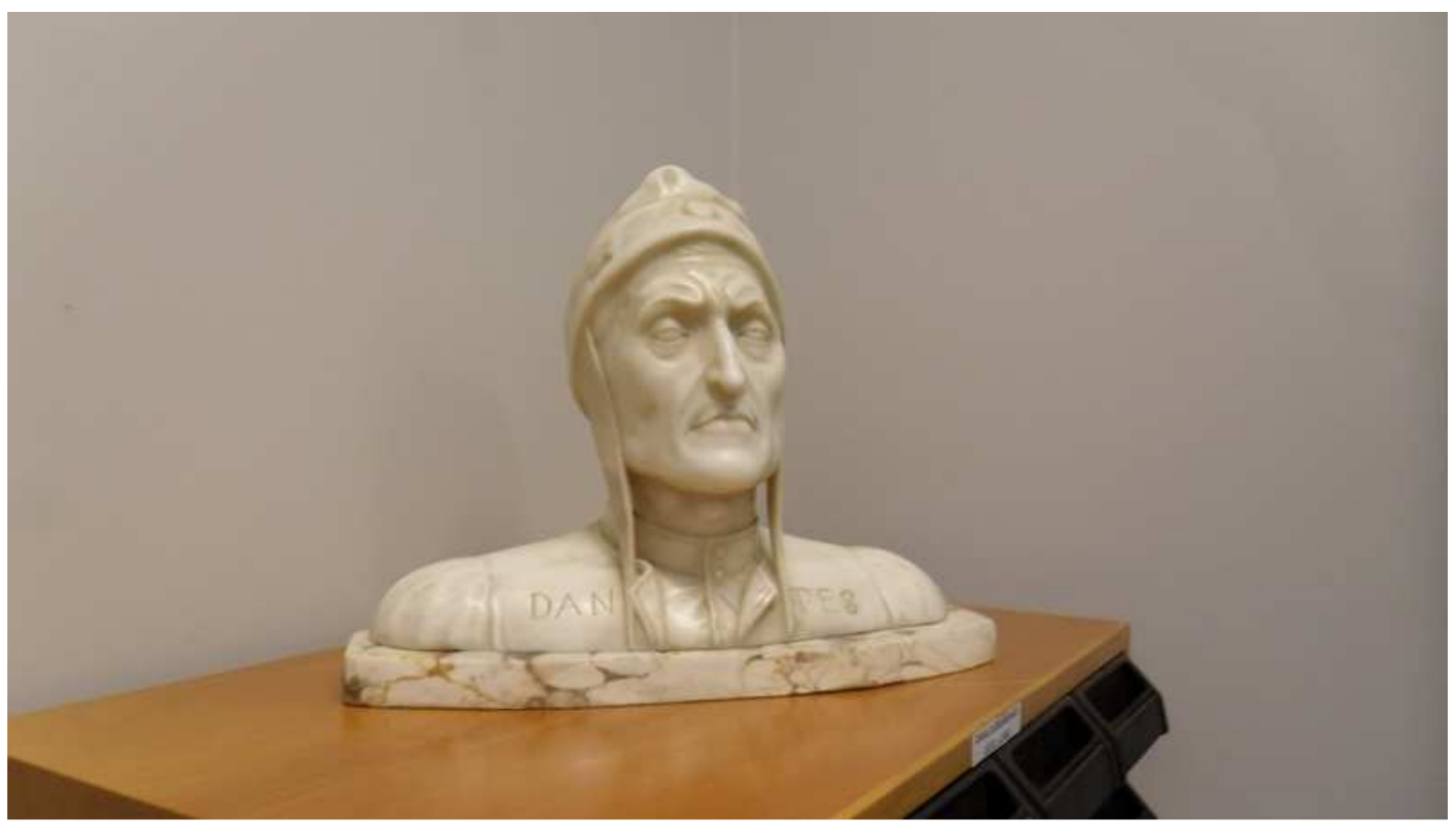

8. Bust of Dante (artist unknown, n.d.), Special Collections Room, Ground Floor, General Library 


\section{Motivations for displaying artwork in the academic library setting}

The librarians interviewed reveal diverse opinions about the reasons for displaying artwork in the General Library, possibly reflecting the extent to which the institution's mission goals for their Art Collection are being effectively communicated and understood by staff. It also illuminates the librarians' personal views as to why the artwork is placed in the General Library. This enquiry, which examines why librarians feel an institution collects and displays artwork in their libraries, partially replicates similar issues explored in the previous literature and brings a novel consideration to this research area: how do librarians view the relationship between the institution as art-owner and the display of artwork in the library?

Liljenwall's suggestion that "[universities] as places of learning, social activity, and cultural exchange, pursue collection building to ... offer physical embodiments of [their] philosophy and beliefs" (p. 1), is roundly acknowledged by the librarians and the Director in their respective interviews. The motivation driving the University of Auckland to purchase artworks goes beyond solely 'art for art's sake' or for investment. The Director confirms this by declaring:

"We cannot always guarantee on works going up in value over time, so we see the development of the collection as investment in the integrity of the Collection itself, not for financial reasons."

The librarians also support this perspective: the General Library's artwork should be displayed to enhance the physical environment. One librarian claims "the artwork here adds liveliness. I think that the University should keep that goal, to display, in mind when they buy art - it shouldn't be for just the bank vault". This consideration, of prizing the value of displaying artwork over the sheer investment potential it may have, is a major driver in the acquisitions policy guiding the buying of new artworks for the University. The Director states that:

"[Our] motivations for acquisition are essentially related to the integrity of the Collection as an ongoing process, and so we look at how a work can add to the integrity of the Collection, that it will make sense, and is coherent with what we already have, and that it has its own kind of dynamism and relates to who we are as an institution". 
However, another librarian refutes these goals, expressing a more cynical perspective:

"Having the artwork here is a subtle vehicle for the University - there is definitive status-building on show, and that's clear from the size of some of the works. But because you have to find it, there is an almost self-effacing quality there - a quiet unveiling of considerable wealth".

The Art Collection establishes the institution as a key cultural player, provider of artistic tuition and an esteemed art patron as it aims to collect 'major' artworks by alumni or artists that have a close association to the University. This relationship, between the artist and the University, is noted on the labels beneath each work, where the artists' status as a former student or teacher at the University (and dates of teaching periods or graduation) are emphasised. Several of the librarians express the opinion that this policy of displaying the artwork of previous students and teachers of the University was "extremely worthwhile". One librarian states that:

"As well as being a showpiece for the University's investment, putting the artwork of old students here supports the arts community, and it shows to the current students that the University is interested in their artistic endeavours, and that we invest in our young people".

Another librarian suggests that another motivation for the display of artwork in the General Library must be the associated connections generated by such presentations. The librarian declares:

"The artwork here makes the library feel a more serious and formal place - a professional place. Plasma screens or advertisements for Coca-Cola create a bus shelter effect. To see works of higher minds is probably inspiring - and that's an effect that occurs with the artwork here".

These incidental secondary connotations associated with artwork in the General Library add credence to the concept that the artwork is a tangible, albeit transportable, extension of the built academic environment. The artwork becomes synonymous with the identity the University is cultivating: a serious, dignified and culturally-aware institution and this is reinforced by its display throughout its campuses, public spaces and offices. This is acknowledged by the Director as she states: 
"We are always buying with a role to eventual placement in the University, but the artwork must have its own integrity - and we don't let the existing structures dictate the artwork. We try to buy the best possible art which relates to our mandate and guidelines, and then look for locations".

However, while the collection is growing in size and scope, the interviews indicate that a central mission of the Art Collection has not been properly relayed to library staff. The librarians express some confusion over the history and ownership of the artwork in the General Library. Many are unsure as to whether the artwork is owned by the Library due to its long-standing placement and in the case of some works, their designed site-specificity. The librarians offer their thoughts on the creation of the General Library's collection, which varies from fair accounts to urban legends repeated from long-past staff members. This ambiguity of purpose is problematic for the library as it limits the artwork from being used to its full potential as information materials. Interviews with the librarians indicate that many of the staff have vague ideas as to the extent of the Art Collection, the types of works it includes, the body that controls the maintenance and ownership rights, and whether certain works can be requested for special positioning in their workspaces. This is in spite of the promotion of the Art Collection's 'From the Collection', a regular column featuring selected works in a campus-circulated newsletter, and digital initiatives such as the mobile application tour of noteworthy works around the institution.

The librarians interviewed universally express the view that greater promotion of the University's artwork, in either formalised mediums such as exhibitions or through digital initiatives such as databases, will encourage greater awareness of the Art Collection and meet a primary objective of the Collection to "provide a high standard of management of a major University and national asset" (The University of Auckland, 2012). One librarian states that:

"It would be great to have more information about the artwork available in an easily searchable form, where you could find out more about the works by typing in key descriptors, rather than relying on the tiny labels that are already in the General Library - if you can find or see them, that is".

This issue is also raised by art advisor Camille Ann Brewer's research into fine art collection management in public libraries. Brewer's 2011 research suggests that libraries often "miss" an obvious opportunity to promote their art collections, stating that: 
"[Libraries] as leaders in information management with a mission to collect and protect material culture, it was surprising to see the number of institutions that do not catalog [their] art objects" (2011, p. 77).

This failure to provide publically-accessible catalogs or reveal the extent of the artwork collected for educational intent and managed by the library, Brewer argues is "a missed opportunity because, when these objects are not perceived as library materials, their existence is invisible to potential users" (p. 77). Brewer's advice is:

"Given the overlapping philosophies for collecting, cataloguing and disseminating information, libraries should be more diligent in handling objects which may be valuable financial assets for the institution" (2011, p. 77),

This guidance is not deliberately or unconsciously ignored in the General Library, but rather a fully accessible catalog is unrealistic due to practical, rather than theoretical reasons. The Director indicates that financial constraints and the difficulties of securing legal copyrights to representations of the Art Collection, means that the artwork is not fully catalogued and the extent of the Collection is not made publically accessible. In this connection, the Director acknowledges that as:

"The University library as an entity, shifts to have a greater digital and online presence, we are being asked to make the artwork digitised in some way. Unfortunately, it is way bigger than my stretched time and resources will allow to dedicate money to putting the artwork online for the sake of having it online - I fully endorse that, but unlike the library with their e-readers and digital materials collections, the Art Collection simply does not have the digital expertise or the finances to fund it".

Despite these reasons, one librarian suggests that the artwork in the General Library could "tap into the digital nature of where the University's libraries are going" in a relatively subtle, affordable manner. She suggests that the museum-style labels that are affixed to the wall beside each artwork include Quick Response (QR) codes, where users could scan their smart phones and be taken to the University of Auckland's existing webpage of their Art Collection, or to another page that would link to details about the specific artwork - some of which are already extensively covered in the existing digitised articles from University newsletters. The Director also suggests that the addition of a digital touch-screen kiosk in the foyer area that showcases examples from the General Library, located in a site with heavy foot traffic and alongside the existing Window exhibition space, would be a welcomed and 
much-used gateway to the Art Collection's bounty - but is currently a financially unachievable initiative. However, recent moves to represent parts of the Art Collection on a worldwide digital collections repository is a significant step toward making the artwork of the General Library known to newer, and responsive audiences. Such initiatives could be linked in the future to the General Library homepage, and would raise awareness of artwork in the library and support the University's intentions to "foster general awareness and understanding of the visual arts" amongst the University community, and the broader public (The University of Auckland, 2012). 


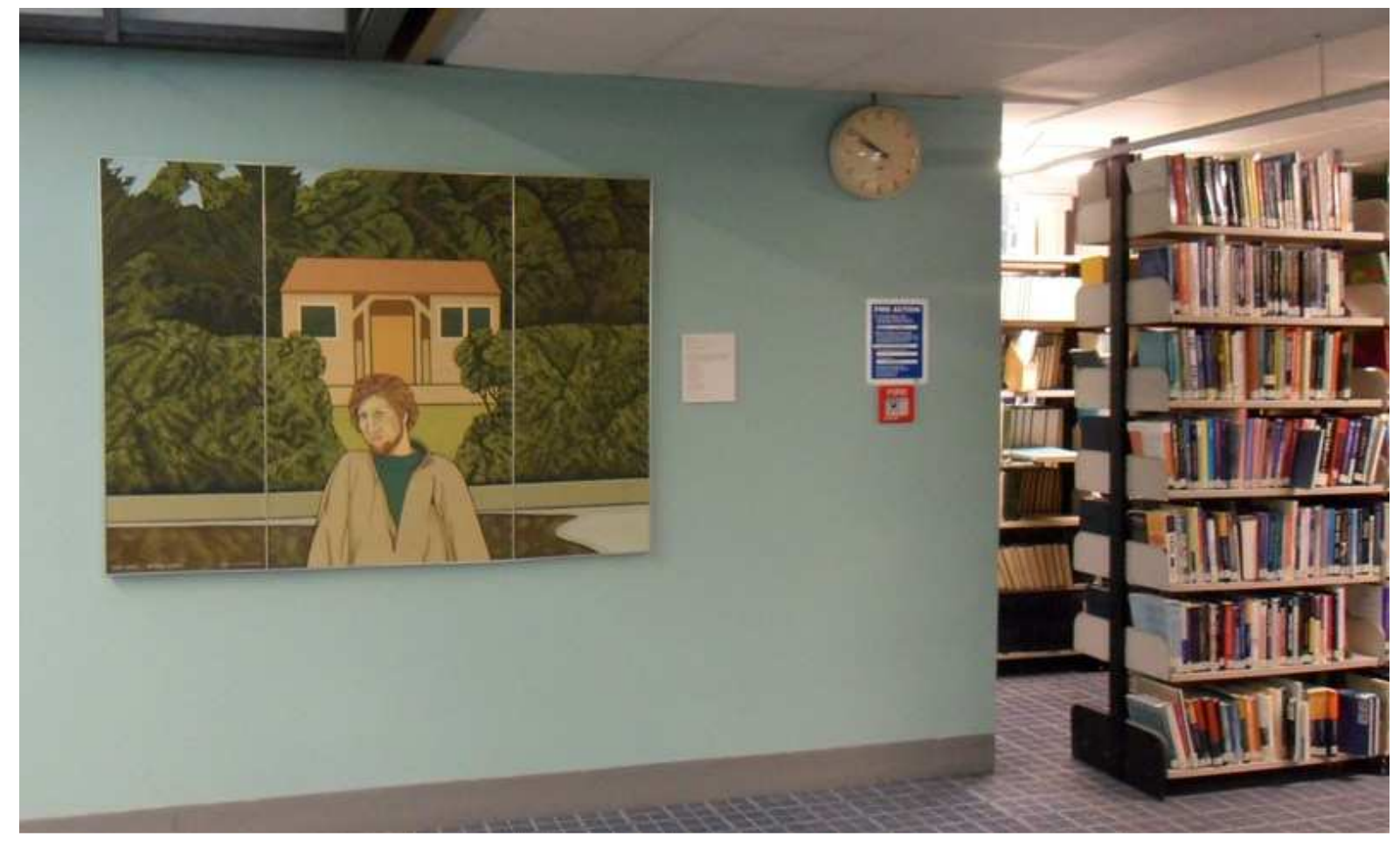

9. Sam Hunt, Bottle Creek by Robin White (1970), First Floor, General Library

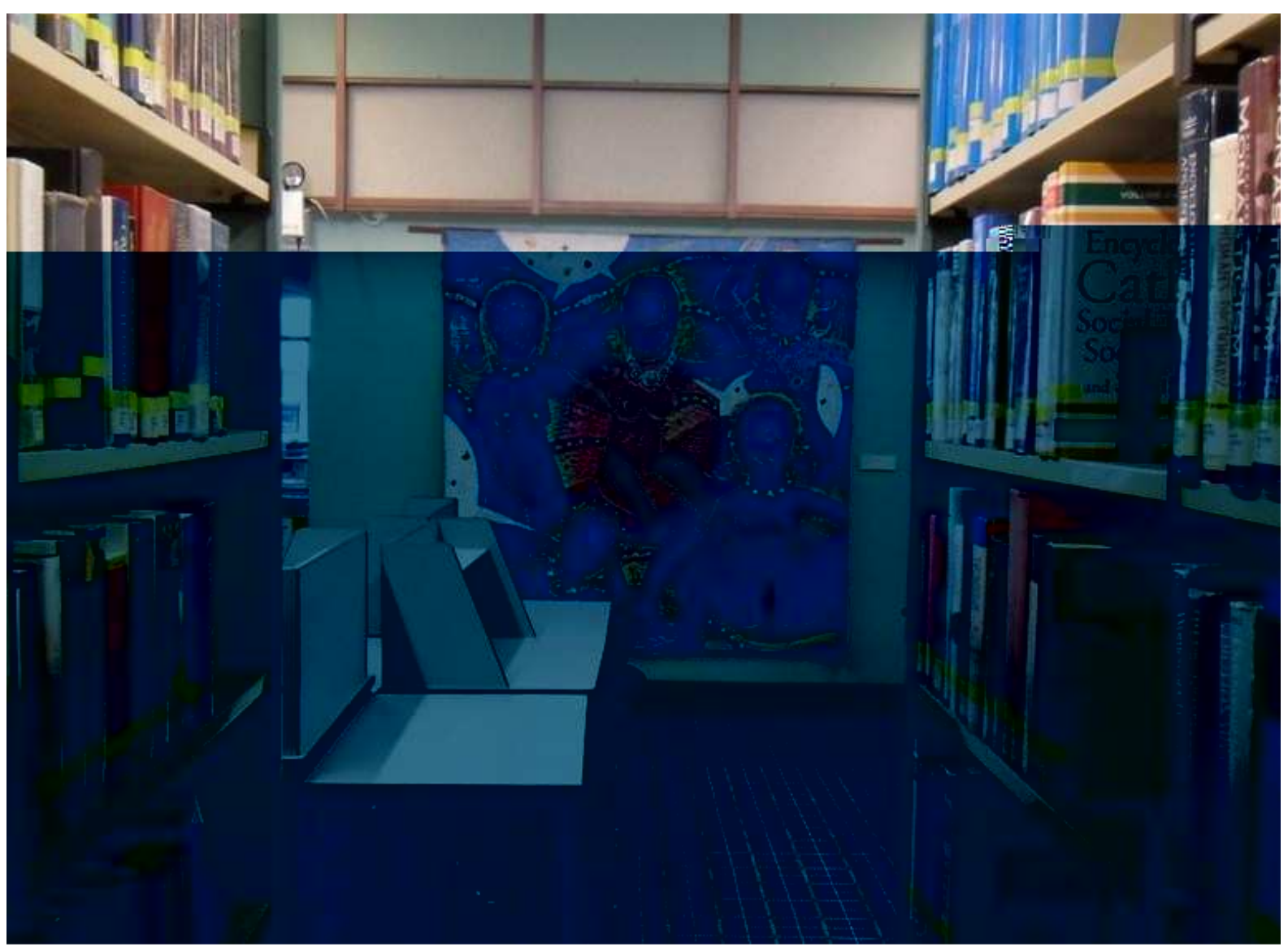

10. Blade Healers by Rohan Wealleans (2008), First Floor, General Library 


\section{Challenges of hosting artwork in the academic library}

Unlike the academic libraries studied in the previous mainly American-based literature, where librarians have the responsibilities of arranging, selecting and managing art exhibitions, the artwork in the General Library is centrally managed and maintained by the Art Collection. Thus, the Auckland librarians take on the mantle of custodianship, rather than curatorship. The interview data reveals that this current practice is divisive amongst the librarians, who work with and amongst the artwork on display.

The librarians interviewed support Kam's view that they may struggle in positions with a curatorial role as the traditional remit of librarianship does not offer the skills required of curators, such as "a trained eye, connoisseurship, or knowledge of the "canon' of fine art" (2001, p. 10). Several librarians agree that the subjectivity of curatorship, especially the ability to justify the choices made for display, is something they would be uncomfortable with, or untrained for. Most interviewees mention that the curation and preservation management of the artworks in the General Library should be left to people with specific knowledge. These divisions, between librarianship and curatorship, are indicative of different occupational cultures. However, the interview data indicates a potential for greater collaboration between the librarians and the management of the Art Collection which would benefit both parties. Whilst librarians are disinclined to take on curatorial roles, they are in favour of having greater involvement generally in selecting artwork, or having some representation in artwork. Greater involvement from the librarians in choosing the artwork for the General Library could reinforce the notion of "psychological ownership" posited by art theorist Patricia Phillips (1988, p. 95). This would encourage greater promotion of the artwork by the library to raise its potential as an information resource, and encourage greater awareness of the displays by the librarians. This idea is supported by several librarians, with one stating that while librarians might not know the intricacies of effectively repairing paintings, they should:

"Have greater involvement with the choosing of works for this space, because we know the building well: we could suggest where the best places to put works are -and because so many of the works have been here for a long time, we have taken possession of them in many ways - they are ours, and so maybe the librarians should make sure we look after them better, because they are ours to keep". 
Two librarians are in favour of the General Library overseeing substantially more significant curatorial duties, one arguing for greater maintenance and control, saying:

"We have special collections material within the library, and librarians are attuned to caring for physical objects, not just documents. For instance, a librarian just wouldn't leave a very valuable book open on a table exposed to direct sunlight - and if we had control of the paintings here, we wouldn't do that to them".

The second is also in favour of a liberal interpretation of an academic librarian's role:

"While caretaking isn't a traditional library skill taught, and while it's not a natural inclination, there should be an appreciation for protecting material objects from the librarian's perspective. It's not unheard of for librarians to be caretakers - they wear gloves to handle special collections material - but because control of the art is removed from us, I think that the idea of looking after the artwork is not at the forefront of the librarian's mind".

This perspective is supported by Kam (2001), who acknowledges that while "librarians have not always understood the importance of the object...librarians with training in archives and rare book librarianship can be effective in communicating the value to others the value of the individual object as object" (p. 13). One librarian holds a dissenting viewpoint based on practical difficulties: granting librarians' total curatorial responsibility would present its own challenges as "you'd be throwing it open too broadly - and then it would get stuck in committee stage".

In considering the General Library as an effective repository and showcase for the University's artwork, the Director states that the library is:

"A sympathetic home for the artwork, and a respectful home for a large extent. The preconceptions of libraries are a good thing - there is less likely to be hooliganism going on in them, as libraries are places where people probably behave more cautiously, and they don't throw water bottles around, they don't eat. There is less likelihood that the paintings will be damaged or injured in the library."

Several librarians disagree, arguing that the library is not a good custodian of its artwork, with one librarian stating: 
"I don't think librarians are good caretakers of artwork - we don't display them correctly, the works are not rotated, they get dusty, and we don't really make sure the environment is a safe one".

The vulnerability of the artworks is an issue raised by another librarian, referencing the theft of a number of artworks and art objects from the Special Collections room of the General Library over the 2006-2007 Christmas period, which included a valuable Charles Goldie painting (Field, 2007, p. 7). While the items in this 'art heist' were eventually recovered and returned to the University, the theft highlights the risks inherent in the public display of artwork (New Zealand Press Association, 2007), one interviewee expressing the opinion that:

"The library is not a secure gallery - it is a wholly public building, perhaps even too much a public building. There is no limit on entry, so you can be a guy with a skateboard and a knife and come in just as well as an engineering student can”.

Several other librarians also acknowledge the relative vulnerability of the library space, but the Director notes that theft and vandalism, malicious or accidental, are ever-present calculated concerns that the University must balance due to the distributed nature of the Art Collection. The Director also expresses the view that some of the responsibility associated with hosting artwork must be shouldered by the host department, or building, as:

"The nature of a distributed collection is that you cannot be the eyes and ears of the whole management and security of the collection, we rely on those people to work collaboratively and effectively with us if they want works in their departments or spaces".

This adds further credibility to the earlier suggestion that greater collaboration between the librarians and the management of the Art Collection would result in positive outcomes. 


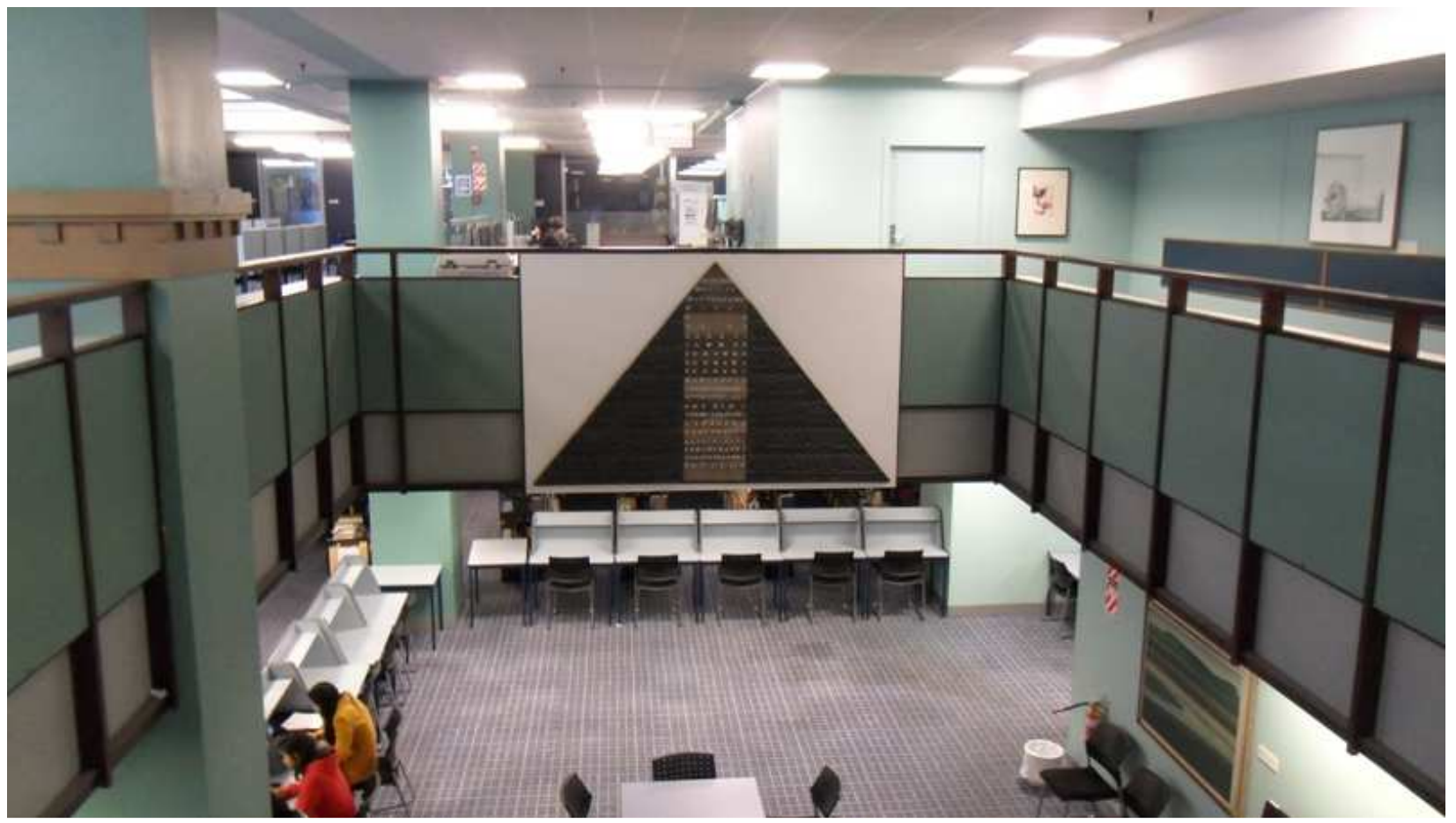

11. How Maui Made the Sun Go Down by Pauline and James Yearbury (n.d.), First Floor (seen from Mezzanine Floor), General Library

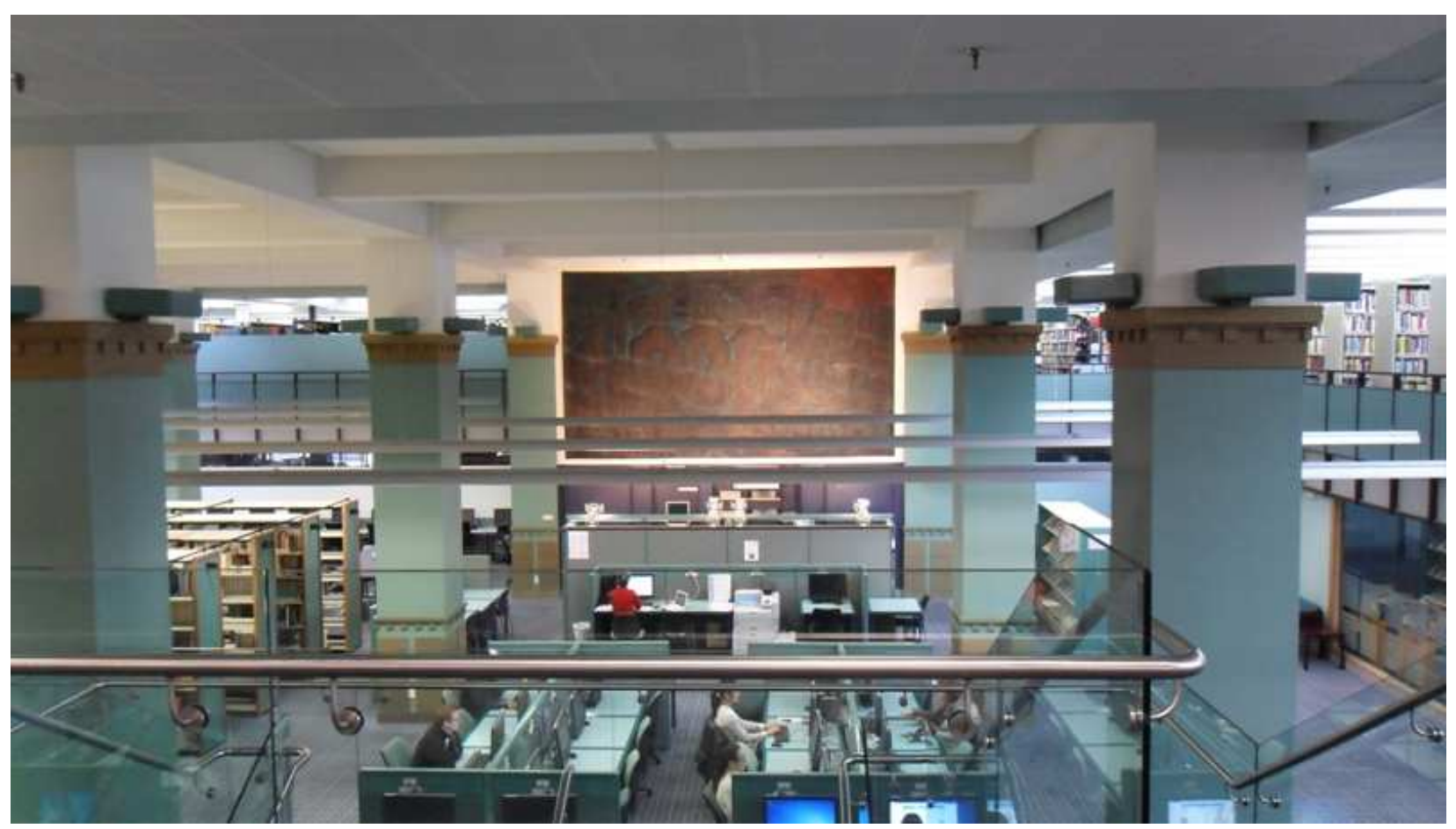

12. He mihi ki nga Wairua Kaitiaki o te Whenua by Selwyn Muru (1997), First Floor (seen from Mezzanine Floor), General Library 


\section{V. $\quad$ Considering the academic library as a public art space}

The data collected clearly establishes the academic library environment as a public art space. The General Library is seen by all interviewees to be a wholly "public" space, as there is no barrier on entry into the building and visitors are allowed to freely browse the physical resources on display there, including books, magazines, journals and newspapers. This freedom of access is held by one librarian to place the library in a uniquely powerful position:

"The library is a public building, there is no limitation placed on entry. It's one of the few buildings in the whole of Auckland where there is no restriction on who can come in. I think that makes this a special building, and as a library with our purpose to educate and provide learning resources, our reach out to the communities beyond just the students and staff here means that we have a duty to carry out our mission to our potential users, or people in the community - the public."

This point, of meeting the needs of the created 'community' of users in the General Library is supported by library consultant Sam Demas (2005). Demas proposes that the library is an important agent in creating a grouping within the greater institutional and public communities, stating:

"Libraries are amongst the busiest, most welcoming spaces on a college campus. Free and open to everyone, they are distinctly non-commercial and operate on a uniquely communitarian character and business model. Well-run and well-designed libraries serve, in effect, as a form of academic community centre" (2005, p. 33).

The General Library's role in Demas' quasi- "academic community centre", 'reaching out' and relating to external publics, can be found in public art theory. The association between the academic environment and a public art space uniquely fits the General Library, which features both the designated public art exhibition of Window and its own displays of publically-viewable artwork. Simor's proposition that the display of artwork in the academic library is "for many students, their first conscious exposure to artwork" (1991, p. 137), adds extra support for seeing the academic library as a public art space. Just as the core conception of public art is to enliven shared public space and to add cultural life to built environments through artwork, the General Library in displaying artwork for these same reasons and for public audiences, engages in public art. 
As a public art space, the General Library reaches sections of the public beyond the already art-aware users who frequent galleries or museums. This proposition is sustained by the view of a librarian who asserts:

"Because this is such a public building, which caters not just to the university community, having artwork here brings an awareness of artwork that is really accessible, and for people from many different cultural backgrounds, it may be the first time they've really come up close and personal with artwork. This a less threatening experience than being in a gallery, and being around the artwork here is a comfortable thing: it just seems as though the art here is normal - and that's how it should be".

Public art theory supports this view and the 'democratising' effect of artwork in public spaces. However, the 'naturalness' of linking the built academic environment with artwork to benefit all users of the space is challenged by two librarians. The first holds that the General Library's artwork is primarily institutional, bought by the University for their purposes of "promotion, or status-building", rather than out of "goodwill or trying to bring art out to the whole community - I think that is more of an added bonus than designed effect". The cumulative effect is that the artwork of the General Library is made "public art by default, because it is publically accessible, publically visible; anyone can walk in here - it's just if they have the gumption to".

The second dissenting librarian holds that the relative lack of awareness about the displayed art is because it is often 'found' by, rather than actively promoted to, communities outside the library's core users. This means that the artwork cannot be "for" the public in the manner of a sculpture in a park. The librarian adds: "I would say the artwork is publically viewable, absolutely - but in terms of whether people know it's here to view, then no, I wouldn't say it's publically accessible in that aspect". This lack of available information about the General Library's collection supports the previous discussion of the relative 'invisibility' of the artwork.

The interview data also indicates that librarians feel that the public nature of the artwork in the General Library presents potential risks. As noted, the Director concedes that the factors of vulnerability, including theft, malicious vandalism or other external damage such as fire or flooding, are necessary risks that must be taken if an institution is desirous of a distributed collection. Several librarians suggest that the placement of certain artworks in the General Library "tempt fate" in their current positions. For example, two librarians single out a three- 
dimensional wall hanging, Blade Healers by Rohan Wealleans (2008) as an inappropriate placement in the General Library. Blade Healers is an artwork that features added material forms, such as rocks, and is sited on the Mezzanine floor to the side of the Arts subject librarians' offices. The work is not completely affixed to its supporting wall; it is this physical vulnerability that was acknowledged by one librarian, stating:

"I'm scared for it - it's such a beautiful painting, but my first thought when I see it is not the beauty of the painting, but rather 'when is it going to be damaged?' It is so vulnerable there, we pass by with trolleys, and the students sit so close to it - it's just a matter of time, really."

Another librarian, who identifies with the dilemma the Art Collection faces when displaying a distributed collection, states that it is clear "that the library has to strike a balance between wanting to allow people to come close and see the artwork in detail - but at the same time protect and look after it". The virtues of display - where the artwork is made known and accessible, and allowed to cast its aesthetic benefits on the users of the library - must be considered in relation to the nature of the building itself, and its original purpose as a functioning library. 


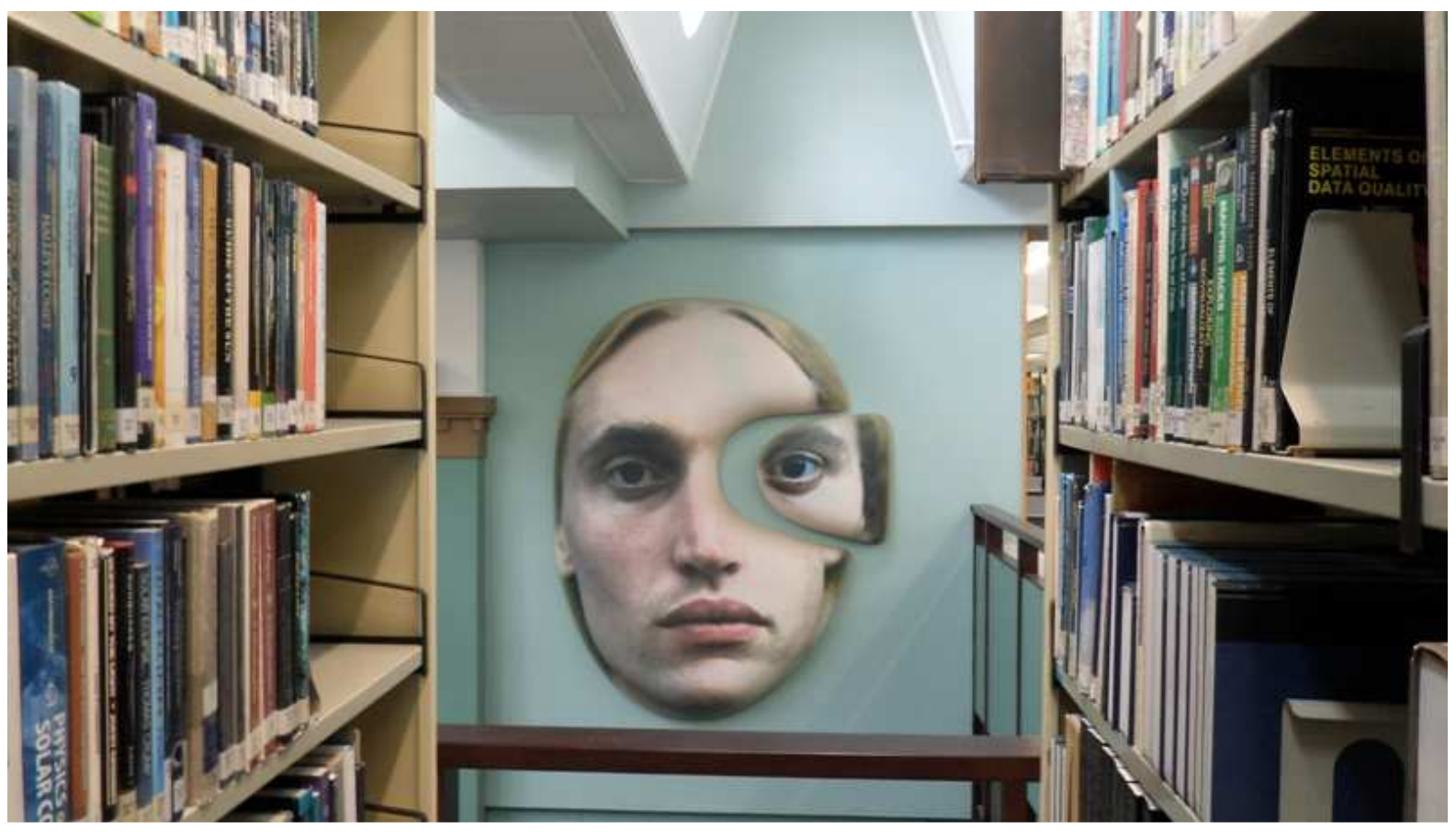

13. Socket by Sarah Munro (2003), First Floor (seen from Mezzanine Floor), General Library

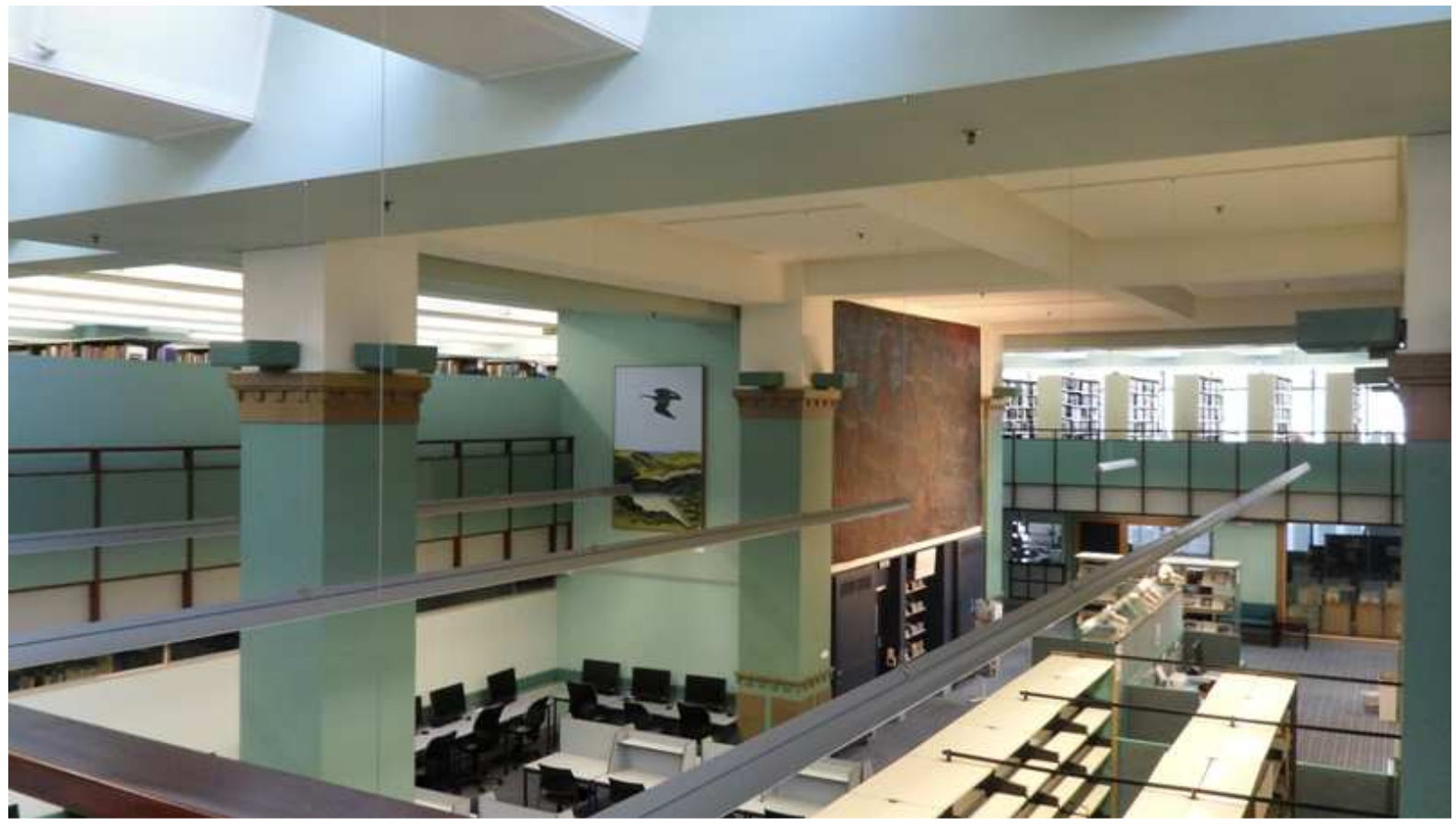

14. Kawaupaku Te Henga by Don Binney (1967, left) and He mihi ki nga Wairua Kaitiaki o te Whenua by Selwyn Muru (1997), First Floor (seen from Mezzanine Floor), General Library 


\section{Looking through the Window}

Following on from the discussion of the General Library as a public space, the Window exhibition presents a series of contrasting opinions. Window is an interesting example of the convergence of the cultural heritage and information sectors, in this instance the relationship between gallery and library space. The views of the librarians interviewed are generally opposed to those expressed by the curators of Window and the Director. The interview data indicates significant occupational divides, which are reflected in the divisive comments made by each group.

Window is a cultivated art exhibition space existing in physical and virtual dimensions (in the library foyer, and online). The exhibitions change monthly, and are curated by a team of young, mostly fine arts graduates. The curators seek to attract emerging student as well as more developed artists, who usually have some affiliation to the institution. The exhibition space was founded in 2003 during the renovation of the library complex, specifically to represent the fine and visual arts community of the university which lacked visual representation on the main campus.

The glass vitrine form of Window occupies a position of prime campus real estate: inside and to the side of the entry foyer area of the library complex, with outside observers able to see the exhibition through glass panelled walls. This high visibility factor of Window brings opposing reactions from the interviewees. The curators celebrate "the highest visitation count of any gallery in the country", albeit largely due to its presence in the transitory foyer area. They feel that artists are faced with a unique challenge to work within a confined and defined physical space - which can lead to interesting artistic interpretations. The librarians however feel that, while Window provides a unique opportunity to showcase contemporary artistic talent, the ambiguity of the space and the perceived ill-thought and ill-conceived artworks chosen are a negative reflection on the General Library. Essentially, Window represents a missed opportunity to create something really wonderful for both the arts community and the library. One librarian confirms the majority opinion in expressing:

"Window is a problematic space, because people think it belongs to the library, and when the art that's in there looks like dust, or cardboard boxes, then it looks like the 
library has forgotten to do its housework. I think it misrepresents the library, as the space is so ambiguous".

The librarian suggests a partial solution, that "proper defined signage could help with that [the ambiguity of the space] - if the space was clearly demarked as an art project, then I am sure our feelings about it would improve". However, promoting the Window space, which the Director calls a "liminal one", with specific signage or promotion is dismissed by the curators. Their view is that, given the current vogue for galleries to be "neutral spaces", Window fittingly follows suit. One curator explains this method stating:

"It seems too didactic to say 'this is a space where artists are showing art', and especially as this is a university where everything is divided into hierarchies, it seems good to break that and have a space that doesn't have visible branding in the conventional way staff or students are used to".

It emerges that the cultural and occupational divide between the Window curators and the librarians contributes to the difficult relationship between the library and Window. The curators hold that Window is completely unaffiliated with the workings of the library, despite its location in the General Library complex. This opinion is reinforced by the Director, who states:

"It is unfortunate that the library chooses to view Window as their space, or as being in their building. Window is in quite a distinct space, it is a separate entity as a gallery. As libraries are all about control, they would like to control Window and discipline it - but it isn't their mandate to do so, it isn't their business to have intellectual or conceptual control."

The perspective of the curators and Director is firmly in favour of considering Window as a public gallery quite separate from the General Library. The contrast of this opinion with that of the librarians reveals the different expectations of the space: the librarians perceive the foyer area (inclusive of Window) as part of the library, whereas the curators and Director view the space as divisible into distinct elements, each capable of being 'owned' by either the Centre for Art Research or the library.

There are reasoned arguments in favour of each position. For the curators and Director, Window offers an unparalleled opportunity to exhibit contemporary art in a highly public and visible area. The curators concede their choice of display "mightn't appeal to all, but it is appropriate to an academic gallery setting - contemporary art is very academic". The curators 
and Director take the opportunity to offer an intellectual and visual challenge for viewers, with one curator saying "we certainly don't offer soft and pretty pictures on the wall". Several librarians also voice support for the Window concept, being appreciative of the regular refreshment of the exhibitions, which is not seen in the library's artwork. One librarian concludes that although Window "caters to an enlightened audience", and ostensibly this is met through its displays, the feelings of the librarians should not be casually discredited.

Kam notes that "exhibitions constitute yet another important vehicle for the expression of the institutional extended self" (2001, p. 12). This is especially relevant in light of the ambiguity of Window and reflects on the 'owner' of the space: the General Library. Several librarians claim that Window does not give the library its due dignity, though some acknowledge that their subjective standards of 'quality' artwork affect their view. The undeniable association that links the General Library with Window is significant, and Kam's proposal that "it is important to ponder what we are communicating, not only about the materials on display, but of ourselves" (2001, p. 12) is particularly pertinent. The impact of Window as an extension of the built academic environment is integral to the functioning of the exhibition - the interview data suggests that users primarily visit Window because it is located in the library's space. The tension between the Window and the librarians, which according to the curators has "changed over time, according to different curators and different librarians", is complex. It draws out sharply opposed expectations of the use of the library space between the occupations and the territorial responses of the respective parties. Liljenwall says that public art of an institution:

"Can reach out and touch the soul. It enriches students, faculty, and the general public, and it communicates to those who view it...a sense of the university's beliefs and philosophy" (2008, p. 58-59).

As a public art space within the University, Window can deliver Liljenwall's view of institutional public art, but the interview data indicates this is no simple task. Window is an example of the difficulties of cross-cultural convergence: the occupational divides of librarianship and curatorship evidently result in a disjointed and unbalanced relationship. Despite this, there is potential for increased and beneficial collaboration. By focussing on the similarities between the roles of curator and librarian - which include their missions to impart and provide information to users - the antagonistic opinions between the occupations might 
thaw. Further efforts to cultivate a relationship between the librarians and curators, like talks by curators to explain the exhibitions of Window, as well as promotion of Window exhibits on the library's digital notice boards, will encourage collaborative efforts for the future, and in the present will act as an acknowledgement of the roles of all stakeholders involved. 


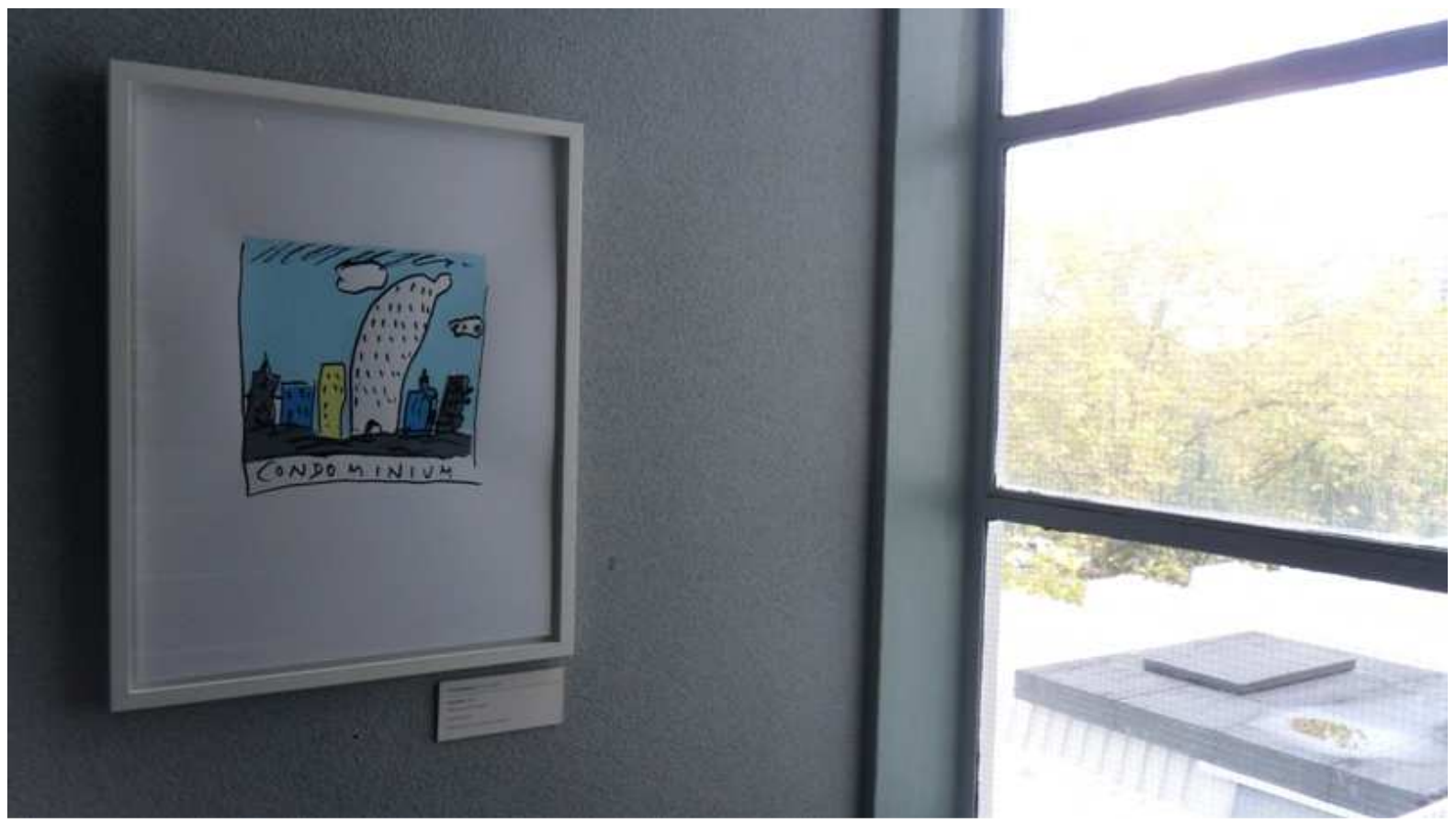

15. Untitled by Tom Kreisler (2008), stairwell between the Second and Third Floors, General Library

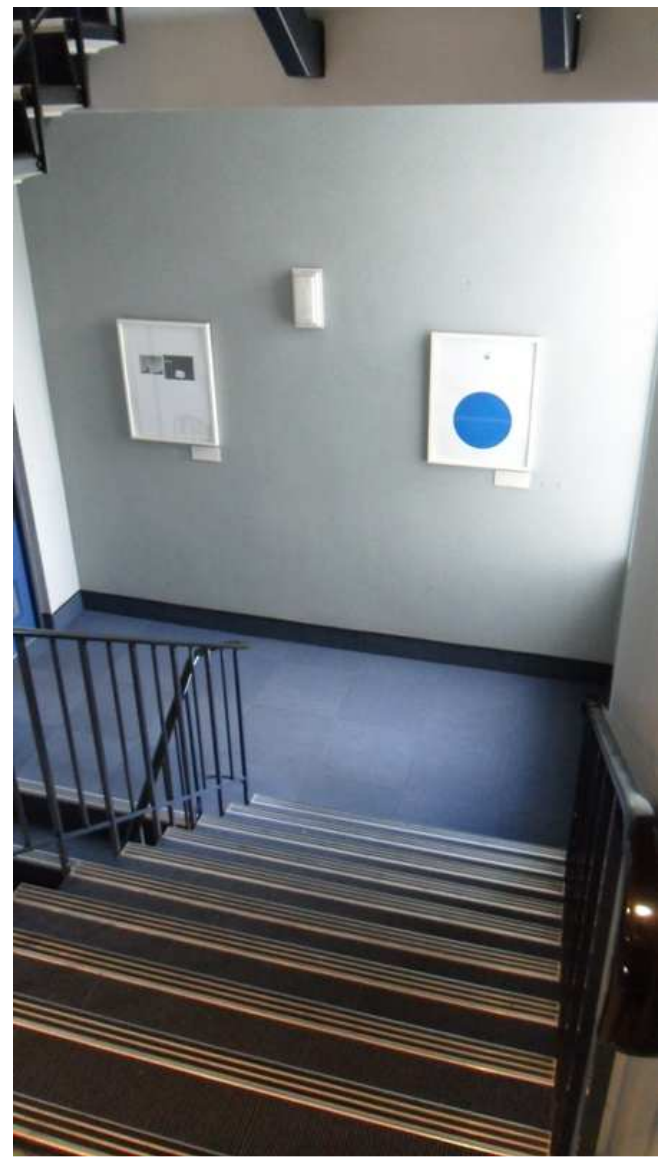

16. Artwork in the stairwell between the Third and Fourth Floors, General Library 


\section{Discussion}

This research project explores a range of issues related to the practice of displaying artwork in academic libraries. Using a novel combination of Art History and Information Studies, the data collected confirms the value of artwork to the academic library environment and its broader purpose to amplify and enhance the visual, cultural and aesthetic life of the hosting institution.

The central research questions:

- Is it relevant for an academic library to display artwork?

- Is there a purpose for artwork in the academic library?

- What benefits, and pitfalls, are seen as a result of an academic library hosting artwork?

- Can academic libraries be public art spaces?

are explored in semi-structured interviews and observations of the display of artwork in the General Library. The research questions are integrated in the interview and data collection process, which also incorporated key questions from the relevant literature. The findings concur with some of the conclusions of previous researchers, and also advance the argument that the academic library is a public art space. The data collected answers the initial research question, in confirming the contemporary relevance of artwork in the academic library environment. This ranged from librarians' fondness for the 'friendship' made with certain paintings to the capability of artwork to support the library's educative mission. In answering the second research question, the data identifies many purposes for artwork in the library setting. Interviewees describe the ability of artwork to add 'vitality' to the library, and to act as a promotional vehicle for the University's cultural ambitions.

In answering the third research question, the data identifies the many benefits of displaying artwork in academic libraries. For example it provides a sophisticated aesthetic experience for many who may not come into direct contact with well-known New Zealand and some international artists. However, the data also identifies pitfalls, which include the constant risks of theft or damage, the staidness of the collection, and the difficult relationship between the curators of the Window exhibit and the librarians in terms of the curatorial vision 
expressed. The final research question is also answered by the data, which (supported by public art theory) establishes the position that academic libraries can be public art spaces, largely due to the public's accessibility to the artwork displayed.

The findings also provide insights into the perceptions of academic librarians and other related parties to displays of artwork in an academic library. The results are relevant, providing practical and theoretical benefits, by affirming the contemporary relevance of the academic library and the importance of artwork to its physical setting. The multiple reasons ascribed to the role and positioning of artwork reflected by the interviewees, challenges researchers who have predicted the 'death' of the physical academic library space due to advances in technology and changes in user demographics.

The results of this research project establish the liveliness and activity of the academic library and how artwork is essential to support its core missions and those of the host. The interview data shows that the important role of artwork displays helps explain why they have become 'default' features in an academic library. The project also considers the opinions of librarians - a relevant group of stakeholders whose thoughts on the practice of displaying artwork has been largely absent in the previous Information Studies literature. 


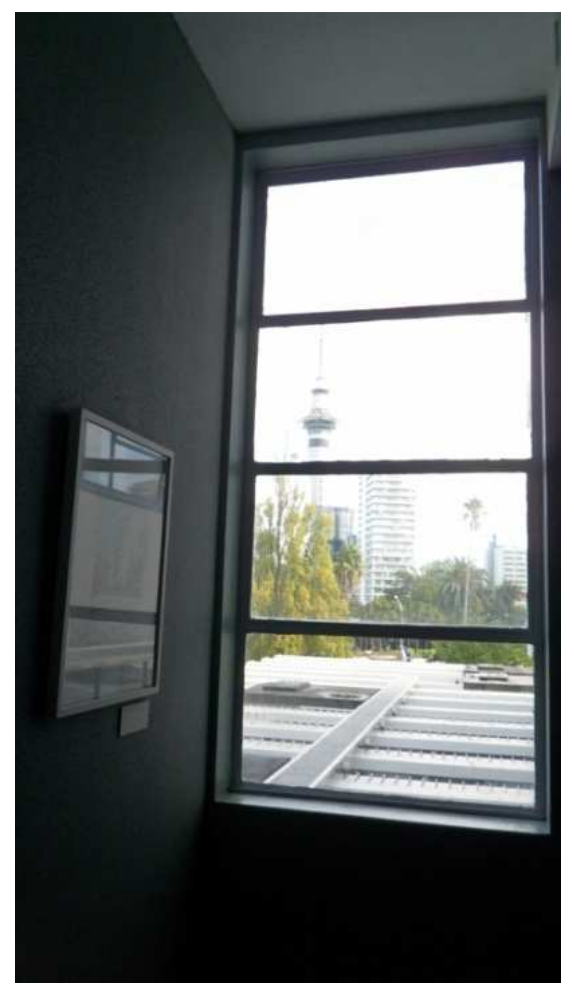

17. Photograph showing the distribution of sunlight into the stairwells (pictured: the stairwell between the Second and Third Floors), General Library

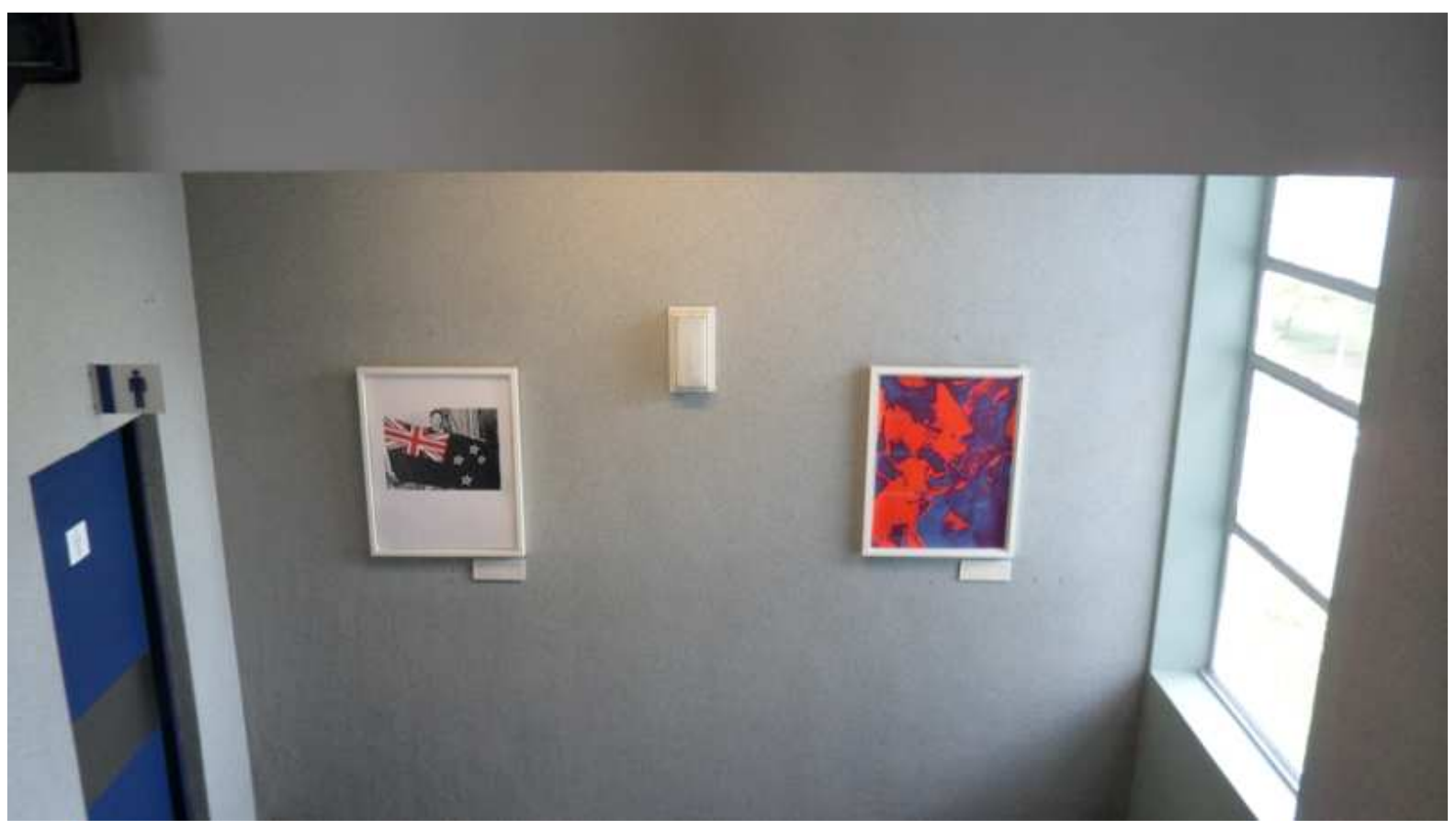

18. Untitled by Daniel Malone (left, 2008) and Untitled by Ronnie van Hout (right, 2008), stairwell between the Fifth and Sixth Floors, General Library 


\section{Recommendations for future research}

The value of the theoretical and practical approach taken in this project establishes a firm base for future research. The findings will benefit by an extended investigation framed outside of the case study approach, to compare the impact and perceived relevance of artwork in academic libraries in higher educational institutions throughout the country. Future research could also extend the other exploratory theme of this project by investigating whether the architectural development of libraries contributes to the creation of gallery-type spaces in the library and extends the concept of the academic library as a public art space. Future research could analyse the ideas of architects or institutional designers to establish how the physical space of an academic library is decided, and how artwork can support the actual and aesthetic shape and functioning of modern libraries.

The model of collaborative convergence for the information and cultural heritage sectors, which is presented here as a source of conflict for the General Library and the Window exhibition space, is another key area for future investigation. The differences seen between the occupational cultures and expectations of librarians and curators, expressed in disagreements over ownership of library space and territorial attitudes, are significant to contemporary Information Studies literature. Additionally, future research could further explore user expectations of the library space, which introduces notions of how the library environment is perceived, and whether artwork impacts users of the library. This would involve extending the participant group beyond librarians to these other users. There is great potential to extend these recommendations in higher level tertiary study, particularly in interdisciplinary doctoral research. 


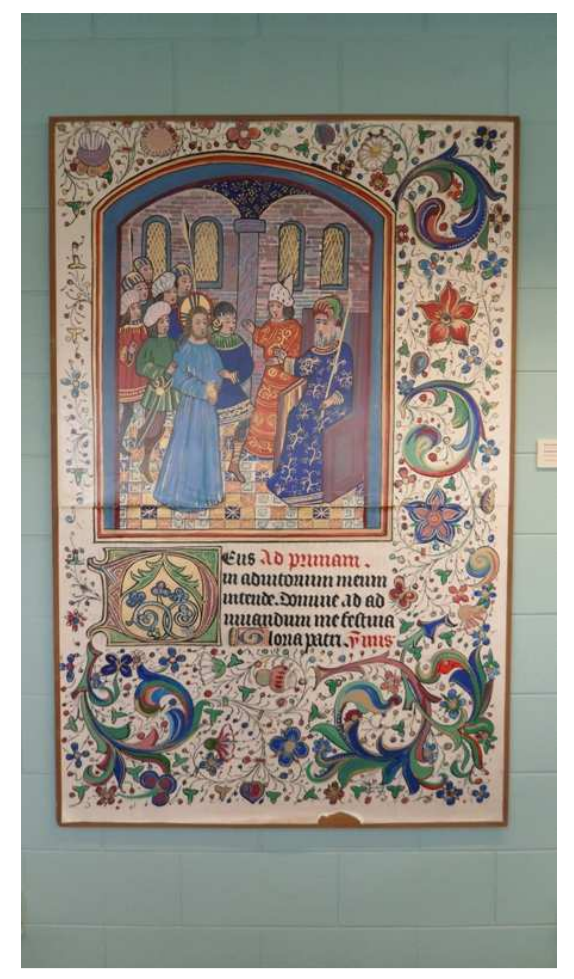

19. Enlargement from the Book of Hours by Helen Sandall (1969), Fifth Floor, General Library

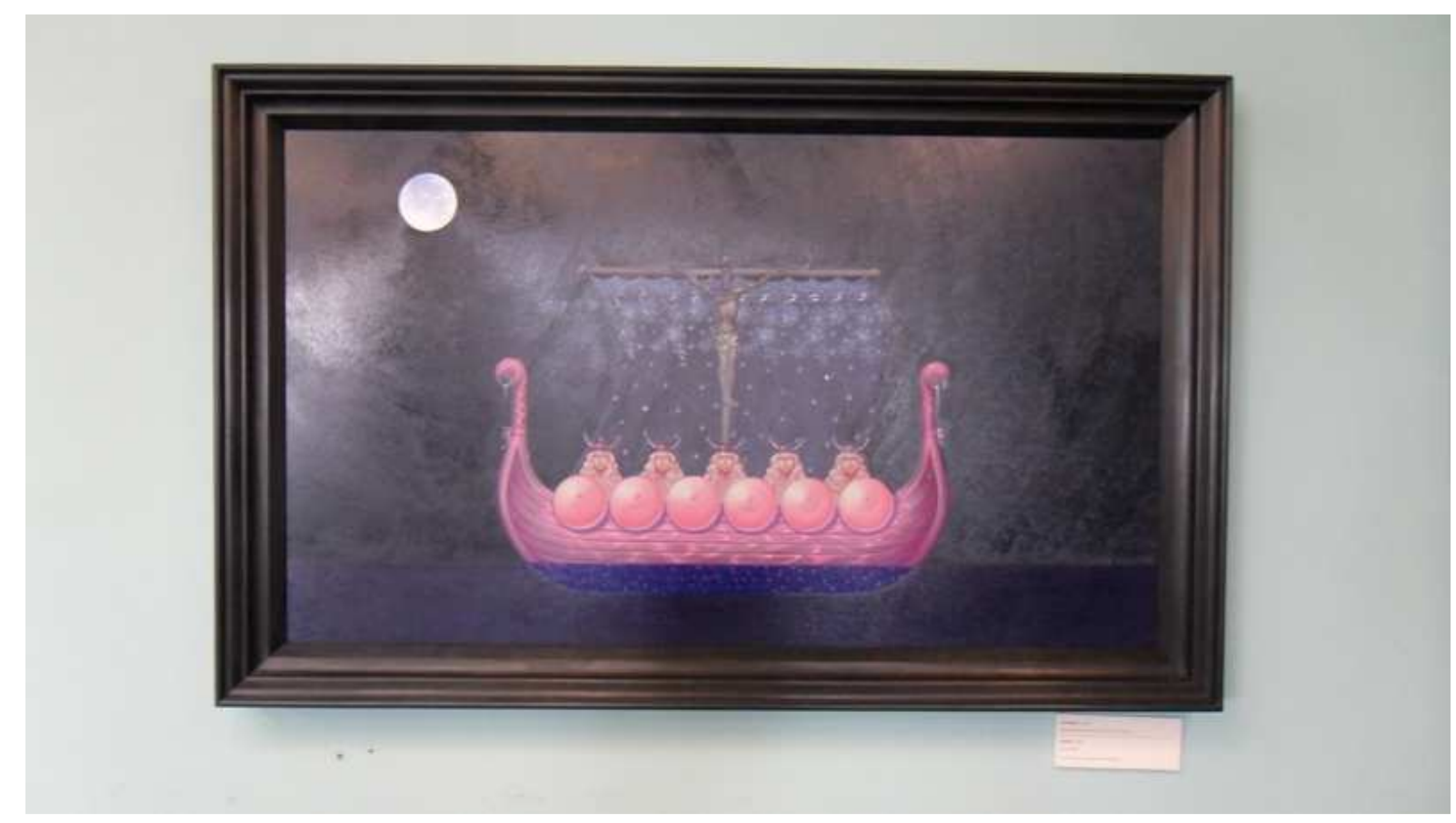

20. Sirens by Liz Maw (2009), Sixth Floor, General Library 


\section{Conclusions}

The justifications for the continuing and future practice of displaying artwork in academic libraries are firmly established by this research project. The value of artwork and art objects being publically accessible is essential and relevant to academic libraries, as they offer ideal opportunities to enrich the library experience for users, as well as enhance an institution's cultural life. The strength of the opinions taken from practising librarians working in the General Library of the University of Auckland substantiates these conclusions. These views range from the perceived impacts on user comfort in the library to the role that artwork has in the higher educative missions of an academic institution. The results of this research project additionally affirm that the physical presence of artwork in an academic library creates an aesthetically pleasing environment for students, staff, faculty and members of the public that is conducive to the pursuit of intellectual endeavour and cultural enrichment. 


\section{Bibliography}

Beech, J. (2009). Inside out. Art Monthly, 329, 1-4.

Benedetto Beals, J. (2007). Student art in the library juried exhibition program. Art Documentation: Journal of the Art Libraries Society of North America, 26 (1), 56-58.

Brewer, C.A. (2011). Fine art collection management in urban public libraries. Art Documentation: Journal of the Art Libraries Society of North America, 30 (2), 74-78.

Bryman, A. \& Burgess, R.G. (Eds.). (1994). Analyzing qualitative data. London and New York: Routledge.

Bryman, A. (2008). Social research methods. Oxford: Oxford University Press.

Cates, J. (2003, June/July). Staff speaks volumes with "Art of the Library". American Libraries, 57-58.

Chhay, B., Pirl, C., Dempsey, M., \& Kember, A. (2006). Visible invisible: Artworks from the University of Auckland Art Collection. Exhibition catalog. Auckland, Gus Fisher Gallery.

Cirasella, J., \& Deutch, M. (2012). From art on the wall to something for all: How an academic library turned its art collection into a campus attraction. Journal of Library Innovation, 3 (1), 1-16.

Demas, S. (2005). From the ashes of Alexandria: What's happening in the college library? In Council on Library and Information Resources (Eds.) Library as place: Rethinking roles, rethinking space (pp. 25-40). Washington: Council on Library and Information Resources.

Dillon, C., \& Gardner, C.A. (2004). Living with art. Virginia Libraries, 50 (3), 2.

Doxtater, D. (1990). Meaning of the workplace: Using ideas of ritual space in design. In P. Gagliardi (Ed.) Symbols and artifacts: Views of the corporate landscape (pp. 107127). New York: de Gruyter.

Dunn, M. (1983). The University of Auckland art collection. Art New Zealand, 26, 47-49.

Eigenbrodt, O. (2008). Societal places: The construction of library space through activity. In World Library and Information Congress: $74^{\text {th }}$ IFLA General Conference and Council, 10-14 August 2008 (pp. 1-17). Quebec, Canada: International Federation of Library Associations.

Elteto, S., Jackson, R.M, \& Lim, A. (2008). Is the library a "welcoming place”? An urban academic library and diverse student experiences. Portal: Libraries and the Academy, $8(3), 325-337$.

Field, M. (2007, January 6). Art heist at university. The Press, A7. 
Fitchett, T. (2002). Monet, Manet, mayonnaise: Is art worth the controversy? Virginia Libraries, 48 (2), 10-13.

Freeman, G.T. (2005). The library as place: Changes in learning patterns, collections, technologies and use. In Council on Library and Information Resources (Eds.) Library as place: Rethinking roles, rethinking space (pp. 1-9). Washington: Council on Library and Information Resources.

Gayton, J.T. (2008). Academic libraries: "Social" or "communal?" The nature and future of academic libraries. The Journal of Academic Librarianship, 34 (1), 60-66.

Goulding, C. (2002). Grounded theory: A practical guide for management, business and market researchers. London: Sage Publications Ltd.

Hein, H. (1996). What is public art?: Time, place and meaning. The Journal of Aesthetics and Art Criticism, 54 (1), 1-7.

Hein, H. (2006). Public art: Thinking museums differently. Lanham: AltaMira.

Jinbo, C., \& Mehrens, C. (2007). Art in the Indiana State University Library: Why have original artworks in an academic library? Indiana Libraries, 26 (2), 40-42.

Kam, D. V. (2001). On collecting and exhibiting art objects in libraries, archives, and research institutes. Art Documentation, 20 (2), 10-15.

Kemp, J. (1994). Art in the library: Should academic librarians manage art? Journal of Academic Librarianship, 20 (3), 162-166.

Kiefer, K. (2006). Art on campus 101: Aesthetics, identity, and lessons learned. Public Art Review, 17 (2), 16-19.

Krause Knight, C. (2008). Public art: Theory, practice and populism. London: Blackwell.

Liljenwall, S.D. (2008). Exploring best practices for building a university's public art collection. Unpublished master's thesis, University of Southern California, California, USA.

McKenzie, S.P. (2006). The University of Auckland Art Collection: Forty years. Unpublished master's thesis, The University of Auckland, Auckland, New Zealand.

Mellon, C. A. (1986). Library anxiety: A grounded theory and its development. College \& Research Libraries, 47 (2), 160-165.

Miles, M. (1997). Art space and the city: Public art and urban futures. London and New York: Routledge.

New Zealand Press Association. (2007, January 5). Goldie painting stolen from Auckland University. The New Zealand Herald. Retrieved from http://www.nzherald.co.nz/nz/news/article.cfm?c_id=1\&objectid=10417877 
New Zealand Press Association. (2007, October 23). Stolen art returned to Auckland Uni. Stuff. Retrieved from http://www.stuff.co.nz/national/54181/Stolen-art-returned-toAuckland-Uni

Phillips, P. (1988). Out of order: The public art machine? Art Forum, 27 (4), 92-96.

Raskin, H. (2009). Can an art gallery thrive in a science library? College \& Research Library News, 70 (4), 226-229.

Rettig, J. (2004). Art for everyone's sake. Virginia Libraries, 50 (3), 4-5.

Rice, R. (2010). The state collections of colonial New Zealand art: Intertwined histories of collecting and display. Unpublished doctoral thesis, Victoria University of Wellington, Wellington, New Zealand.

Simor, S. (1991). Art exhibitions in academic libraries: A necessary (?) luxury (?). Art Documentation, 10 (3), 137-139.

Sorensen, L., \& Avens, I. (1987). On running a small art gallery in an academic library. Art Documentation: Journal of the Art Libraries Society of North America, 6 (3), 121123.

The University of Auckland Library. (2012). Membership and conditions of access to The University of Auckland Library. Auckland, New Zealand: Author.

The University of Auckland Library. (2012). Membership and conditions of access to The University of Auckland Library. Auckland, New Zealand: Author.

The University of Auckland. (2011). The University of Auckland Art Acquisition Collection and Commissions Policy. Auckland, New Zealand: Author.

The University of Auckland. (2012). Guidelines to the University of Auckland art acquisition collection and commissions policy. Auckland, New Zealand: Author.

The University of Auckland. (2012). Rules and directions for use in the University Library and Information Commons. Auckland, New Zealand: Author.

The University of Auckland. (2013). Window. Retrieved May 30, 2013, from http://window.auckland.ac.nz/about.html

The University of Auckland. (n.d.). Brief history of the collections, Retrieved May 30, 2013, from http://www.library.auckland.ac.nz/about-us/our-organisation/brief-historycollections

Thomas, D.R. (2003). A general inductive approach for qualitative data analysis. Retrieved from the University of Auckland School of Population Health:

http://www.fmhs.auckland.ac.nz/soph/centres/hrmas/_docs/Inductive2003.pdf

Thornton, D. (1997). The scholar in his study: Ownership and experience in Renaissance Italy. New Haven and London: Yale University Press. 
Tyler, L. (2012). Art app at your fingertips. Retrieved May 30, 2013, from http://www.ingenio-magazine.com/art-app-your-fingertips/

Wilsher, M. (2009). Beyond public art. Art Monthly, 331, 11-14.

Wyszomirski, M.J. (1982). Controversies in arts policymaking. In K.V. Mulcahy \& C.R. Swaim (Eds.) Public policy and the arts (pp. 11-31). Boulder: Westview Press. 


\title{
Appendix I: Participant Information Sheet (academic librarians)
}

\author{
SCHOOL OF INFORMATION MANAGEMENT \\ LEVEL 5, RUTHERFORD HOUSE, PIPITEA CAMPUS, 23 LAMBTON QUAY, WELUNGTON \\ POBOX 600 , Welington 6140, New Zealand \\ Phone +6444535103 Fax +64.44635446 Email sim@vww.ac.nz Website wwivictoria,acnz/sm
}

Information sheet for research participants: academic librarians

'Art in the Academic Library' (working title)

Researcher: Celia Austin: School of Information Management, Victoria University of Wellington

Hello,

I am a Masters student in Information Studies at Victoria University of Wellington. As part of this degree I am undertaking a research project which critically explores the practice of displaying artwork in academic libraries using the University of Auckland General Library as a case study to:

- analyse the perspective of librarians and other related parties to the relevance of artwork in libraries;

- explore the nature of such libraries as a publically-accessible art spaces.

I am inviting full-time qualified librarians, working in the General Library, who have an interest or awareness of the artwork on display there to participate in my study, and provide their insights into the issues that confront librarians hosting artwork.

The Human Ethics Committee at Victoria University of Wellington has approved this project. The approval of the University of Auckland Librarian has been attained to carry out these interviews during the work time of the participants, which must be done at the convenience of the interviewee.

The primary vehicle for obtaining the views and opinions of participants will be achieved via a semistructured interview that will be recorded digitally and then transcribed. The interview process is estimated to take a maximum of 30 minutes in total. Unfortunately, due to time constraints it may not be possible to arrange an interview with all interested participants.

This is an entirely voluntary study, and participants have the option of withdrawal before data analysis is complete (May 1 2013). All responses made in the interview process will be kept strictly confidential to both myself and my supervisor Shannon Wellington. The written results of this project will be audited strictly by both parties to assure participant confidentiality.

The researcher is entirely responsible for the transcription of the interviews. It is possible that, after the interview process, additional consultation may be required to clarify points made in the initial interview. All participants will be offered a final copy of the research project. A print and electronic version of the completed research project will be deposited in the Victoria University Library, and may be published in academic journals or the findings presented at professional conferences. The recorded data and transcriptions thereof will be held in secure facilities or in protected electronic files for a period of two years at which point it will be destroyed.

If you have any questions or would like to receive further information about the project, please contact me at austinceli@myvuw.ac.nz or my supervisor, Shannon Wellington, at the School of Information Management at Victoria University of Wellington, P O Box 600, Wellington, at Shannon.Wellington@vuw.ac.nz, phone (04) 4636862.

Kind regards

Celia Austin 


\section{Appendix II: Participant Information Sheet (curators of Window)}

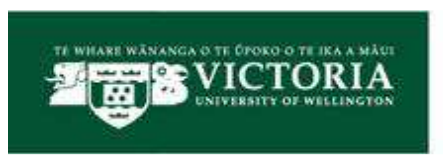

SCHOOL OF INFORMATION MANAGEMENT

TEKURA TIAKO, WHAKAWHTII KC̈NERO

LEVEL 5, RUTHERFORD HOUSE, PIPITEA CAMPUS, 23 LAMBTON QUAY, WELUNGTON

$\mathrm{POB}$ Box 600 , Werington 6140, New Zealand

Phone +6444635103 Fax +64.4 .4635446 . Email sim@vww.ac.nz Website wwwivictoria,acnz/sm

\section{Information sheet for research participants: curators of Window}

\section{'Art in the Academic Library' (working title)}

Researcher: Celia Austin: School of Information Management, Victoria University of Wellington

Hello,

I am a Masters student in Information Studies at Victoria University of Wellington. As part of this degree I am undertaking a research project to be carried out over a period of two trimesters. My research project critically explores the practice of displaying artwork in academic libraries using the University of Auckland General Library as a case study to:

- analyse the perspective of librarians and other related parties to the relevance of artwork in libraries;

- explore the nature of such libraries as a publically-accessible art spaces.

The Human Ethics Committee at Victoria University of Wellington has approved this project. I am inviting the curators of the Window gallery space in the Library to participate in the study and provide their insights into the issues that confront curators involved in the art exhibition spaces in the General Library complex.

This research project will provide novel and interdisciplinary insights which will benefit library practitioners, and contribute to the growing scholarly interest in viewing academic libraries as multipurpose spaces. The primary vehicle for obtaining the views and opinions of participants will be achieved via a semi-structured interview that will be recorded digitally and then transcribed. The interview process is estimated to take a maximum of 30 minutes in total.

This is an entirely voluntary study, and participants have the option of withdrawal before data analysis is complete (May 12013 ). All responses made in the interview process will be kept strictly confidential to both myself and my supervisor Shannon Wellington. The written results of this project will be audited strictly by both parties to assure participant confidentiality.

The researcher is entirely responsible for the transcription of the interviews. It is possible that, after the interview process, additional consultation may be required to clarify points made in the initial interview. All participants will be offered a final copy of the research project. A print and electronic version of the completed research project will be deposited in the Victoria University Library, and may be published in academic journals or the findings presented at professional conferences. The recorded data and transcriptions thereof will be held in secure facilities or in protected electronic files for a period of two years at which point it will be destroyed.

If you have any questions or would like to receive further information about the project, please contact me at austinceli@myvuw.ac.nz or my supervisor, Shannon Wellington, at the School of Information Management at Victoria University of Wellington, P O Box 600, Wellington, at Shannon.Wellington@vuw.ac.nz, phone (04) 4636862.

Kind regards

Celia Austin 


\title{
Appendix III: Participant Information Sheet (Director for the Centre of Art Research)
}

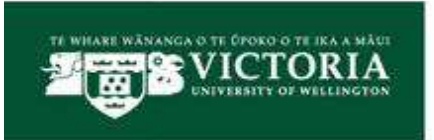 \\ SCHOOL OF INFORMATIONMANAGEMENT \\ TEKURA TIAKO WHAKAWHTI KÖ \\ LEVEL 5, RUTHERFORD HOUSE, PIPITEA CAMPUS, 23 LAMBTON QUAY, WELUINGTON \\ POB Box 600 , Werington 6140, New Zealand \\ Phone +64.44535103 Fax +64.4.463 5446. Email sim@vww.ac.nz Website wwwivictoria, acnz/sm
}

Information sheet for research participants: Director for the Centre of Art Research

'Art in the Academic Library' (working title)

Researcher: Celia Austin: School of Information Management, Victoria University of Wellington

Hello,

I am a Masters student in Information Studies at Victoria University of Wellington. As part of this degree I am undertaking a research project to be carried out over a period of two trimesters. My research project critically explores the practice of displaying artwork in academic libraries using the University of Auckland General Library as a case study to:

- analyse the perspective of librarians and other related parties to the relevance of artwork in libraries;

- explore the nature of such libraries as a publically-accessible art spaces.

The Human Ethics Committee at Victoria University of Wellington has approved this project. I am inviting the Director for the Centre of Art Research to participate in the study and provide insights into the motivations for, and issues that arise from the General Library complex hosting artwork.

This research project will provide novel and interdisciplinary insights which will benefit library practitioners, and contribute to the growing scholarly interest in viewing academic libraries as multipurpose spaces. The primary vehicle for obtaining the views and opinions of participants will be achieved via a semi-structured interview that will be recorded digitally and then transcribed. The interview process is estimated to take a maximum of 30 minutes in total.

This is an entirely voluntary study, and participants have the option of withdrawal before data analysis is complete (May 1 2013). All responses made in the interview process will be kept strictly confidential to both myself and my supervisor Shannon Wellington. The written results of this project will be audited strictly by both parties to assure participant confidentiality.

The researcher is entirely responsible for the transcription of the interviews. It is possible that, after the interview process, additional consultation may be required to clarify points made in the initial interview. All participants will be offered a final copy of the research project. A print and electronic version of the completed research project will be deposited in the Victoria University Library, and may be published in academic journals or the findings presented at professional conferences. The recorded data and transcriptions thereof will be held in secure facilities or in protected electronic files for a period of two years at which point it will be destroyed.

If you have any questions or would like to receive further information about the project, please contact me at austinceli@myvuw.ac.nz or my supervisor, Shannon Wellington, at the School of Information Management at Victoria University of Wellington, P O Box 600, Wellington, at Shannon.Wellington@vuw.ac.nz,phone (04) 4636862.

Kind regards

Celia Austin 


\section{Appendix IV: Participant Consent Form}

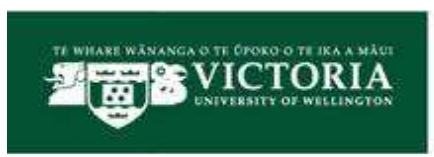

SCHOOL OF INFORMATION MANAGEMENT

TEKURA TIAKO, WHAKAWHITI KC̈FERO

LEVEL 5, RUTHERFORD HOUSE, PIPITEA CAMPUS, 23 LAMBTON QUAY, WELUINGTON

POBOX 600 , Welington 6140 , New Zealand

Phone +64.44535103 Fax +64.4.463 5446. Email sim@vww.ac.nz Website wwwivictoria, acnz/sm

\section{Participant Consent Form}

\section{'Art in the Academic Library' (working title)}

Thank you for agreeing to participate in my research.

The Human Ethics Committee at Victoria University of Wellington has approved this project.

I have been provided with adequate information relating to the nature and objectives of this research project, I have understood that information and have been given the opportunity to seek further clarification or explanations to my satisfaction. I understand that I may withdraw any information I have provided from this project before May 12013 without having to give reasons, and that any data provided will be destroyed.

I understand that any information I provide will be kept confidential to the researcher and the supervisor, and the published results will not use my name, and that no opinions will be attributed to me in any way that will identify me wherever reasonably possible.

I understand that the recorded data will be held in secure facilities or in protected electronic files for a period of two years at which point it will be destroyed unless I indicate that I would like them returned to me. I understand that I have been offered a final copy of the research project once it has been completed.

I understand that the information I provide will not be used for any other purpose or released to others without my written consent other than those mentioned in the information sheet.

I agree to take part in this research.

Signed:

Name of participant (please print clearly):

Date: 